National Libı ary

of Canada

Acquisitions and

Bibliographic Services Branch

395 Wellington Street

Ottawa. Ontario

KIA ONA
Bibliothèque nationale

du Canada

Direction des acquisitions el

des services bibliographiques

395, rue Wetlinglon

Ollawa (Ontario)

KIAONA
You the vivienterence

Qun ine Notre ielerence
NOTICE

The quality of this microform is heavily dependent upon the quality of the original thesis submitted for microfilming. Every effort has been made to ensure the highest quality of reproduction possible.

If pages are missing, contact the university which granted the degree.

Some pages may have indistinct print especially if the original pages were typed with a poor typewriter ribbon or if the university sent us an inferior photocopy.

Reproduction in full or in part of this microform is governed by the Canadian Copyright Act, R.S.C. 1970, c. C-30, and subsequent amendments.
La qualité de cette microforme dépend grandement de la qualité de la thèse soumise au microfilmage. Nous avons tout fait pour assurer une qualité supérieure de reproduction.

S'il manque des pages, veuillez communiquer avec l'université qui a conféré le grade.

La qualité d'impression de certaines pages peut laisser à désirer, surtout si les pages originales ont été dactylographiées à l'aide d'un ruban usé ou si l'université nous a fait parvenir une photocopie de qualité inférieure.

La reproduction, même partielle, de cette microforme est soumise à la Loi canadienne sur le droit d'auteur, SRC 1970, c. C-30, et ses amendements subséquents. 


\title{
Topographic Mapping of the Brain Activity of Perceived Motion
}

\author{
Caroline A. Zanni \\ Department of Educational and Counselling Psychology \\ A Thesis Submitted to the \\ Faculty of Graduate Studies and Research, \\ McGill University, Montreal \\ in partial fulfillment of the requirements of the \\ degree of \\ Master of Arts
}

July, 1995

(1) Zanni, 1995 
National Library

of Canada

Acquisitions and

Bibliographic Services Branch

395 Wellington Streel

Ottawa, Ontario

KIA ON4
Bibliothèque nationale

du Canada

Direction des acquisitions et

des services bibliographiques

395, ne Wellington

Ottawa (Ontario)
The author has granted an irrevocable non-exclusive licence allowing the National Library of Canada to reproduce, loan, distribute or sell copies of his/her thesis by any means and in any form or format, making this thesis available to interested persons.

The author retains ownership of the copyright in his/her thesis. Neither the thesis nor substantial extracts from it may be printed or otherwise reproduced without his/her permission.
L'auteur a accordé une licence irrévocable et non exclusive permettant à la Bibliothèque nationale du Canada de reproduire, prêter, distribuer ou vendre des copies de sa thèse de quelque manière et sous quelque forme que ce soit pour mettre des exemplaires de cette thèse à la disposition des personnes intéressées.

L'auteur conserve la propriété du droit d'auteur qui protège sa thèse. Ni la thèse ni des extraits substantiels de celle-ci ne doivent être imprimés ou autrement reproduits sans son autorisation.

ISBN $\quad 0-612-12104-6$ 


\begin{abstract}
The study compared electrical brain activity of subjects in five different conditions: eyes-closed at rest, eyes-open at rest, looking at a flashing object, looking at apparent movement, and looking at real movement. Absolute theta and alpha power in the frontal and occipital areas were analyzed. Significant differences were found in the frontal area. Results suggest that perceived movement requires higher order cognitive processes outside the occipital area. Implications for education and cognitive research are discussed.
\end{abstract}




\section{Résumé}

Cette étude compare l'activité électrique cérébrale des sujets dans cinq conditions différentes: avec les yeux fermé (au repos), avec les yeux ouvert (au repos), en regardant le mouvement apparent, et en regardant le mouvement réelle. $L^{\prime}$ alpha et la thêta en pouvoir absolue, dans la région frontal et occipital du cerveaux, seront analysées. Les résultats obtenues démontre que la perception du mouvement est aidé par des processus cognitives cérébrale, en dehors de la région occipital. Pour fin d'éducation les conséquences de ces résultats sont analysés, tandis que des suggestions pour la recherche cognitives sont formulées et des propositions sont donné pour poursuivre cette étude.. 


\section{Acknowledgements}

As with any research project, this study was a collaborative effort. I would like to sincerely thank all those who assisted me in my endeavour.

First, I would like to thank all the volunteers from McGill University who each gave up three hours of their time to participate in this study. Without them it would have been impossible to conduct this study.

I would like to thank Diana Tabatabai for all her help in teaching me about electroencephalography (EEG) and how to set up the electrodes properly using the International Ten-Twenty System. I would also like to thank Sasha John for his help in this study. His assistance in teaching me about EEG and advising me on the experimental design was truly appreciated.

I would like to extend a sincere word of gratitude to Dr. Frank Ervin, who with his numerous years of experiences in this field was willing to listen to my ideas and help me. His kind words and calm disposition were always reassuring.

I would also like to thank Dr. K.T. Mullen who helped me gain a better understanding of the visual and perceptual processes, and Dr. A. Owen who helped me gain insight into the structures of the brain.

I would like to extend my most sincere appreciation to my thesis supervisor, Dr. Glenn F. Cartwright. His assistance and continuous support throughout the research was extraordinary. My heart felt gratitude to Dr. 
Cartwright for all his support in helping me complete my thesis.

I would like to extend a special word of thanks to all my family. To my husband, Paul Dansereau, who was my technical support any time I needed assistance with the computers, and who was truly supportive of my research. To my children, Francesca, William, Gabriel an extra special thank you for helping me learn the electrode placement system. I would also like to especially thank my parents who helped me and were always a source of inspiration and reassurance, words can not properly express my gratitude. 


\section{Table of Contents}

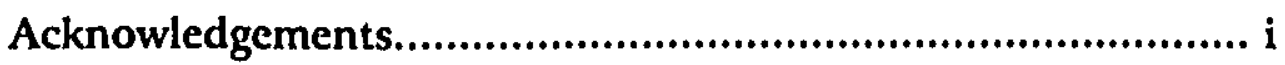

List of Tables.......................................................................

List of Figures..............................................................viii

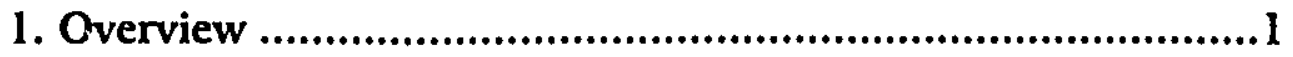

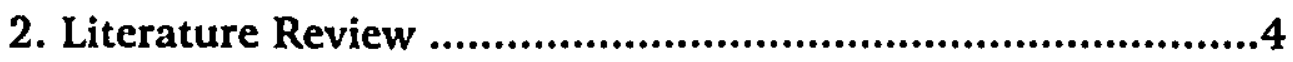

The Implications of Technology in the Perception

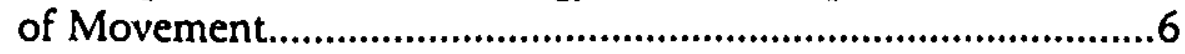

Theories of Apparent Mivement in Reality.............................10

Using Different Areas of the Nervous System.................11

Using the Same Neural Elements......................................14

Quality of the Apparent Movement.................................16

Involvement of the Neural Systems...................................18

Brain Activity and Electroencephalograms ............................19

Cortical Areas Involved in the Perception of

Movement...................................................................19

Electroencephalography and the Perception of Movement.............................................................19

Electrical Brain Activity During Visual Tasks...........................20

Cortical Areas Responsible for the Perception of Movement...................................................................23

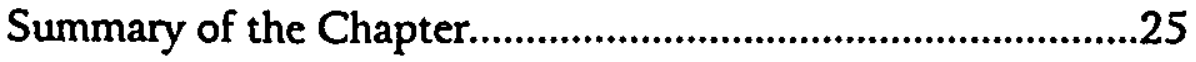

3. Research Methodology.......................................................27

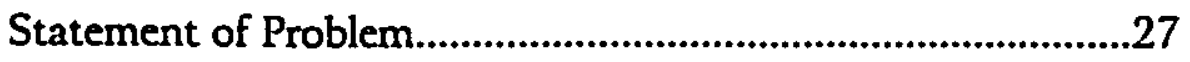

EEG and the Perception of Movement...................................27 
Presentation of Stimuli...............................................................

Description of Stimuli...................................................

The Electrophysiological Monitor ing System.............................34

Procedure

EEG Recordings......................................................36

Recording Montages.........................................................37

Artifact Rejection............................................................ 38

Description of the electrophysiological

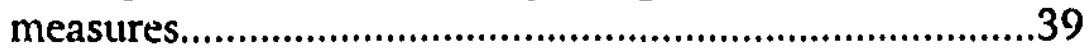

Summary of the Chapter..............................................................39

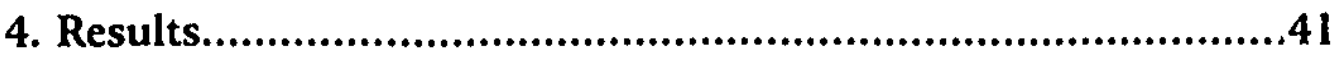

Analysis of Data......................................................................... 41

Analysis of the Resting EEG........................................................43

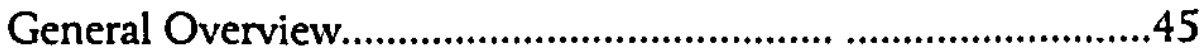

Analysis by Experimental Condition............................................56

Comparison of eyes opened to the three experimental

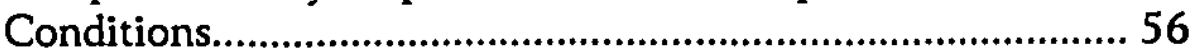

Frontal Area........................................................56

Occipital Area.............................................................63

Comparison between seeing a flashing object

and the threshold of perceiving movement..

Frontal Area..........................................................64

Occipital Area.......................................................67

Comparison between seeing a flashing object and the perception of real movement................................................67

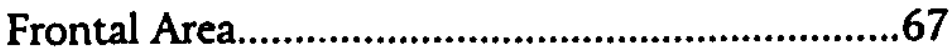

Occipital Area...........................................................69

Comparison between seeing the threshold of perceived movement and perceiving real movement................7C Frontal Area.................................................................71 
Occipital Area..................................................... 73

Parietal Alpha......................................................................73

Summary of the Chapter............................................................. 75

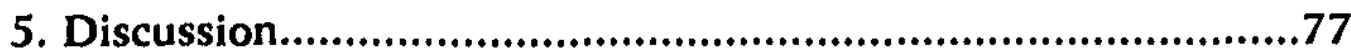

Summary of the Research...........................................................77

Summary of the Results..............................................................78

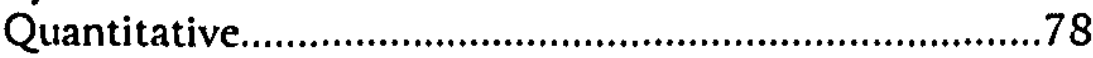

Topographic Brain Maps...................................................79

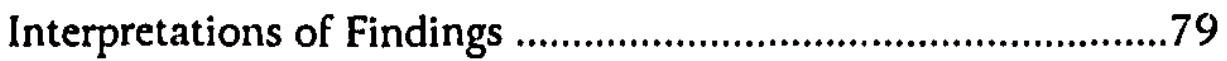

Implications for Cognitive Research............................................83

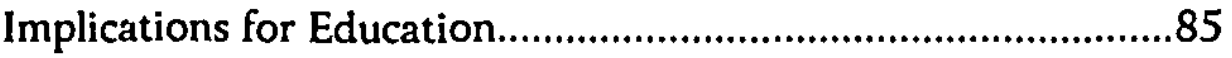

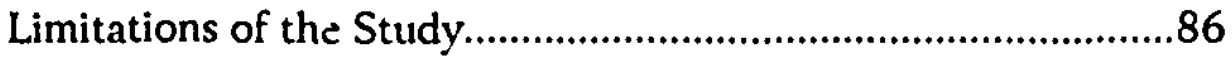

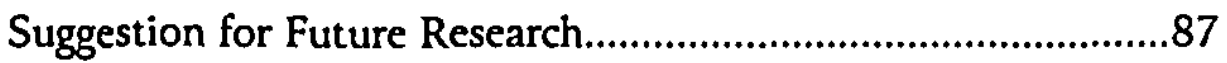

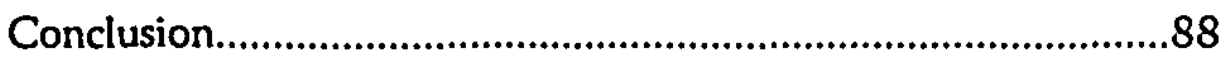

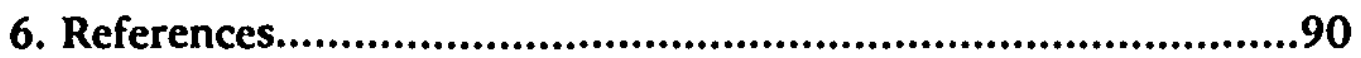

Appendix A - International Ten-Twenty System........................97

Appendix B - FFT Data ....................................................98

Appendix C - Letter of Consent.......................................110

Appendix D Certificate of Ethical Approval.............................11 1 


\section{List Of Tables}

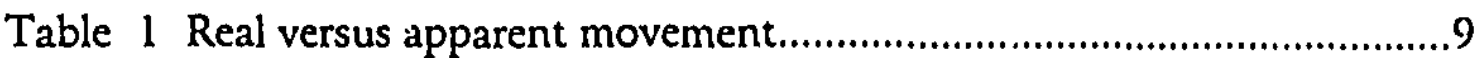

Table 2 Alpha power in the frontal and occipital area Comparison between eyes-open and seeing a flashing object............57

Table 3 Alpha power in the frontal and occipital area Comparison between eyes-open and the threshold of perceived movement

Table 4 Alpha power in the frontal and occipital area Comparison between eyes-open and the perception of real movement

Table 5 Theta power in the frontal and occipital area Comparison between eyes-open and seeing a flashing object.

Table 6 Theta power in the frontal and occipital area Comparison between eyes-open and the threshold of perceived movement.

Table 7 Theta power in the frontal and occipital area Comparison between eyes-open and the perception of real movement.

Table 8 Alpha power in the frontal and occipital area Comparison between seeing a flashing object and the threshold of perceived movement

Table 9 Theta power in the frontal and occipital area Comparison between seeing a flashing object and the threshold of perceived movement 
Table 10 Alpha power in the frontal and occipital area Comparison between seeing a flashing object and the perception of real movement.

Table 11 Theta power in the frontal and occipital area

Comparison between seeing a flashing object and the perception of real movement

Table 12 Alpha power in the frontal and occipital area Comparison between the threshold of perceived movement and real movement.

Table 13 Theta power in the frontal and occipital area Comparison between the threshold of perceived movement and real movement.

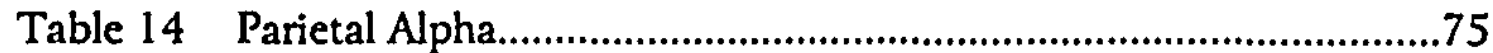

Table 15 Summary of quantitative results....................................................78 


\section{List Of Figures}

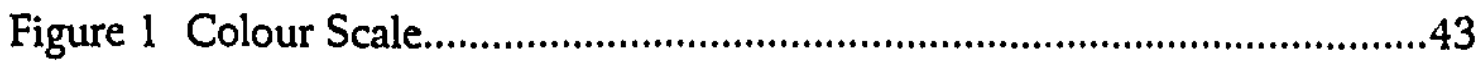

Figure 2 Graph of the subjects that exhibited significant differences between eyes-open to the three experimental conditions changes in frontal alpha and theta.

Figure 3 Graph of the subjects that exhibited significant differences between flashing and the threshold of movement and real movement, changes in frontal alpha and theta....

Figure 4 Graph of the subjects that exhibited significant differences between the threshold and real movement, changes in frontal alpha and theta

Figure 5 Topographic brain map of subject \#1 \#............................................50

Figure 6 Topographic brain map of subject \#2...............................................51

Figure 7 Topographic brain map of subject \#3................................................52

Figure 8 Topographic brain map of subject \#4...............................................53

Figure 9 Topographic brain map of subject \#5.................................................54

Figure 10 Topographic brain map of subject \#6..............................................55 


\section{Overview}

"You are clever, but it comes slowly -- all the way from the back of your head."

- Russian Proverb

Increased knowledge of perception together with advances in technology have produced inotion pictures, television, videogames, and virtual reality (VR) -worlds of illusion based on movement. Many of these visual media are commonly used in classroom settings to augment student learning and new VR technology promises to impact our educational system even more in the near future. Most are based on one common element: movement. However older definitions of movement no longer suffice to explain apparent motion. What is needed is a better understanding of the processes involved in perceiving motion. Toward this end the nature of brain activity in simulated realities will be explored.

Technological simulations of reality allow new and better ways to present movement. But to what degree are they simulating reality? Are they elaborate illusions so close to reality that the brain is unable to tell the difference? Through the study of movement perception in a simulated reality may contribute to an understanding of the implication of such technological changes for our brain. It would be useful to know if simulated movement uses different neural systems in order to better distinguish simulation from reality. 
When motion pictures were invented, there were numerous accounts of movie goers who believed film representations to be real (Vorse, 1911) and some who reacted as if they were real (Palmer, 1909). Most film libraries recount the tale of the first public motion picture exhibition by the Lumière brothers in which terror ensued as audience members confused a motion picture train for an oncoming real train and fled the theatre. Today that would not happen with film literate people; individuals have learned to distinguish the difference beiween motion picture representations and reality. But how? Are there different electrical brain patterns associated with real and apparent perceptions? With new technologies such as virtual reality are such differences detectable?

Electroencephalogram (EEG) technology may provide answers to this question. It allows the recording of brain activity in humans. It can distinguish the areas of the brain which are used to perform certain tasks. In 1929 Hans Burger discovered patterns of electrical activity which could be recorded from electrodes placed at various points on the human scalp. Burger was able to demonstrate that some of the electrical activity recorded originated in the brain itself and was not simply due to musculature (as cited in Springer \& Deutch, 1981).

Since EEGs were first discovered they have been used increasingly in the study of brain activity in both animals and humans. Many of the experimental 
electrophysiology studies have been of a clinical nature, for example the study of electrical brain activity in patients suffering from epileptic seizures (Barlow, 1993). Other studies have used EEGs to examine brain hemisphericity while subjects were involved in either language orientated or visual-spatial tasks (Springer \& Deutch, 1981). More recently researchers have used this technology to examine brain activity related to visual perceptions (Fisch, 1991).

As with all technologies EEG technology has evolved and the development of high speed computers now facilitate the transformation of particular EEG patterns into numerical values. Such values may then be used for statistical analysis and/or for other forms of EEG display such as topographic mapping. This is a more precise way of examining EEG signals which eliminates both inter- and intra-reader variability. It further allows for the computation of statistical tests of significance to detect differences which might not othervise be detected by visual inspection (Fisch, 1991).

Using EEG analysis, this study will examine the perception of apparent versus real movement as reflected in electrical brain activity. The EEGs will be transformed into numerical values using a special computer program from which topographic brain maps will be derived. These maps will be analyzed by visual inspection to detect any differences. Differences in the numerical values will be tested for statistical significance. 


\section{Literature Review}

The perception of apparent movement is an integral part of our daily lives. Through the media of television and film the perception of movement through illusion is an everyday event. With the equivalent of 24 to 30 still frames per second being displayed, each with minimal changes, the perception of movement occurs (Lake, 1994).

The study of apparent movement began before the advent of motion pictures. Exner in 1875 (as cited in Kolers, 1972) examined the perception of movement and argued that the perception of movement is a sensation in its own right, one of the basic constituents of perception, and not a derived or computed one. Exner wished to examine the threshold for temporal succession. For this purpose he exposed two spatially separated electric sparks in sequence, varying the time interval between exposures. During these experiments he found that at a temporal separation of 45 milliseconds (msecs) the observer could report the physical order of the flashes. Exner then went on to measure the lower threshold for this effect and found that observers attributed a direction to the perceived movement when the two flashes were separated by as little as 14 msecs. When the temporal separation was 10 msecs, approximately, the two flashes appeared to be simultaneous.

Wertheimer built on Exner's experiments and his 1912 paper reported an 
astonishingly large number of effects (as cited in Kolers, 1972). This paper launched the movement that became Gestalt psychology and also established the paradigm that is still followed today in many studies of apparent motion. The main variables studied were the stimulus duration, and the spatial and temporal separation of the flashes. His major area of research was in clarifying optimal apparent motion. Optimal apparent motion was defined as an object moving through the physically empty space between the origin and terminus -. from simultaneity at one end and to succession at the other. In apparent motion Wertheimer looked both at phi motion -- global "figureless" or "objectless" motion, and beta motion -. the perception of a well defined object moving smoothly and continuously from one location to another. Optimal apparent motion is synonymous with beta motion.

The theoretical account for apparent motion at one time was thought to be straightforward. Indeed, Korte in 1915 (as cited in Leibowitz \& Teuber, 1978) had formulated a set of principles (now known as Korte's Laws) that were thought to summarize the general characteristics of motion phenomena. Now Korte's Laws are thought to be, at best, gross approximations (Uttal, 1981, p. 915). Korte's Laws define the interrelationships among the three variables of intensity, time, and distance. Specifically: (1) If intensity is held constant, the spatial distance between the lights for optimal apparent movement varies directly 
with the time interval berween lights; that is, if the spatial separation between two lights is increased, the time interval must also be increased or optimal moventent breaks down. (2) If the time interval is held constant, the distance between lights for optimal apparent movement varies directly with intensity. (3) If the distance between the lights is held constant, the intensity for optimal apparent movement varies inversely with the time interval separating the two lights (Schiffman, 1976, p. 261) .

Several studies (Fredman \& Hardy, 1989; Kolers, 1963, 1964; Peterhans \& Hydt, 1991) have shown that the brain processes movement in different ways, and in different cortical areas. Apparent movement, as defined by Wertheimer, seems to have more in common with the area controlling the formation of simple visual figures than it has with real movement. Others (Frisby, 1974; Frisby \& Clatsworthy, 1973; Antsis, 1978; Uttal, 1981) have debated whether the same area or mechanisms are activated during perception of real versus apparent movement.

The Implications of Technology in the Perception of Movement Technology in the past eighty years has accelerated, from silent movies to virtual reality (VR). The definition of virtual reality can range from sophisticated interaction programs on computerized systems to more advanced systcms that 
allow individuals to experience complete immersion in another reality.

VR technology will also impact our educational system just as all other forms of visual media has assisted in changing the educational process. Visual media are commonly used within classroom setting to assist student learning. Now numerous programs using virtual reality are being developed and researched before being implemented in the classroom (Helsel, 1979; Merickel, 1992; Pantelidis, 1993; Regian, Shelbliske, \& Monk, 1992; Spring, 1991; Winn \& Bricken, 1992).

VR technology posses more questions about the perception of movement. With VR closely simulating real movement, the notion of real versus apparent movement must be properly defined. Apparent movement is no longer experienced two dimensionally, in most research designs apparent movement was defined as two flashes of light that when presented at an optimal interval seemed to produced the perception of movement. Now, apparent movement can also be perceived while totally immersed in three dimensions of virtual space.

It is convenient to discuss real and apparent movement in the context of reality and virtual reality. Reality is our everyday experience, devoid of total immersion by any electronic or computerized device. Virtual reality is reality perceived while being immersed in a computerized environment. Real movement in reality is that which is experienced when viewing an object move; it is 
continuous movement. Real movement in VR is the close approximation of actual movement in reality; it approximates continuous movement within a computerized environment. Apparent movement in both reality and VR is any movement that is created by projecting an object at two distinct places such that their projections will hit the retina of the eye at two distinct places, without continuity and at an appropriate threshold of time and distance necessary for the illusion of movement. 
TABLE 1

Real Versus Apparent Movement

\begin{tabular}{|c|c|c|}
\hline & REAL MOVEMENT & APPARENT MOVEMENT \\
\hline REALITY & $\begin{array}{l}\text { continuous movement } \\
\text { with no interruptions. }\end{array}$ & $\begin{array}{l}\text { Two flickering lights with a } \\
\text { larger distance of presentation. } \\
\text { But presented at a fast enough } \\
\text { rate to produce the illusion of } \\
\text { motion. }\end{array}$ \\
\hline $\begin{array}{l}\text { VIRTUAL } \\
\text { REALITY }\end{array}$ & $\begin{array}{l}\text { An extremely close } \\
\text { approximation of } \\
\text { continuous movement. } \\
\text { Presented in a } \\
\text { computerized } \\
\text { environment. }\end{array}$ & $\begin{array}{l}\text { Same as above, but presented } \\
\text { in a computerized } \\
\text { environment. }\end{array}$ \\
\hline
\end{tabular}




\section{Theories of Apparent Movement in Reality}

One of the paradoxes of visual motion perception is that movement over the retina is not a necessary condition for its occurrence. This has been clearly established in laboratory experiments but can also be demonstrated in a number of naturally occurring events. When the moon is observed on a cloudless night it appears to be stationary. However, when the clouds appear over the moon it seems to move. This is called induced movement and it is a clear instance of visual motion without retinal displacement (Wade \& Swantson, 1991).

Therefore, what mechanisms are involved in the perception of movement? In the sixties and seventies a debate over the physiological mechanism underlying the perception of real and apparent movement began. Kolers' (1963) experiments were meant to demonstrate that the mechanisms or brain activities necessary to perceive real and apparent movement were not the same. Frisby's (1973) research attempted to prove that we use the same mechanism, or brain activity, when perceiving real and apparent movement (Schiffman, 1976, p. 262). Kolers and Frisby refer to mechanisms necessary for perception but since perception of movement is "coded" at post-retinal regions of the nervous system (Lettvin, Maturana, McCulloch \& Pitts, 1959 (as cited in Kulers 1963); Hubel \& Wiesel, 1962) the term "brain activity" would be more appropriate than "mechanism". 


\section{Using Different Areas of the Nervous System}

Many writers who have discussed the phenomena of perceiving movement either imply or state outright that since the perceptions of real and apparent movement are indistinguishable one from the other, the underlying mechanisms must be similar or identical (Wertheimer, 1912 as cited in Kolers, 1972); Dimmick \& Scahill, 1925; De silva, 1929; Kennedy, 1936; Gibson, 1954). Kolers $(1963,1964)$ dismissed this notion arguing that the different stimulus conditions for real and apparent movement implied that the "mechanisms" must be also different. Kolers used a masking experiment to test his theory. His findings showed that an apparently moving object is unable to inhibit the detection of a small probe stimulus in the same way as a real moving object. He used a technique of masking to prove this point. The nearer in time and space the different form is presented with respect to the target form, the more difficult it is to see the target form. This phenomenon is called masking. In one variation of it, called backward masking, the second presentation makes it harder to see the first. On the basis of these experiments he made a prediction about a masking task that was moving. The prediction was that a small, stationary line of light in the path of a larger moving line should be harder to see the closer the two are, and the brighter the moving line, the less one should be able to see the stationary line.

Kolers predictions were confirmed. Assuming he would achieve these results he 
asked what would happen to the stationary target if the line of light were in apparent rather than real motion. When the line was in real movement, the probability that the observer would detect the target is least when the two lines and the targets are closest. When the line was in apparent movement, the probability that the observer would see the target is least immediately before the terminus of the apparent movement is flashed on - a time when the apparent movement puts the line well past the target. A line in real movement affects the perception of objects in its path; a line in apparent movement does not. Therefore he concluded that if visual experiences appear alike but are produced by different stimulus conditions, the perceptions may be one produced by different paths in the nervous system. These results are taken to mean that different aspects of a percept are processed in different parts of the brain.

Kolers $(1963,1964)$ defined the difference between real and apparent movement. Real movement is defined as continuous motion across the retina whereby a blur is produced when the movement is rapid. Apparent movement occurs at certain rates of stimulation and there is no motion across the retina. The outcome of his studies imply that the neural mechanism for the two types of perception must be quite different because these identical perceptions seem to be constructed in the nervous system according to different rules. In sum, the brain activity for perceiving apparent motion has more in common with that 
necessary to control the formation of simple visual figures than with real movement.

Further, Friedman and Harding (1989), studying the quality of perceived motion of vertical figures versus oblique-axis figures, as well as mental rotation, concluded that apparent movement seems to be analyzed at a deeper cognitive level than real movement. They found that both apparent motion and mental rotations seemed to share fewer similarities than perceiving apparent versus real motion. They argued that Sheppard and Judd (1976) were premature in concluding that the same mechanism is shared during the perception of apparent motion and the performance of mental rotation. If the perception of real versus apparent motion requires the same mechanism and if as Friedman and Hardy (1989) suggest, also apparent motion and mental rotation do not use the same perceptual mechanism, then it seems unlikely that mental rotation processes have much in common with the processes used during the perception of a real object rotating. Their data indicate that processes used to perceive apparent motion must reflect activity related to a task that is largely automatic in nature, where as a different set of processes is needed to reflect the requirements of a strategic task such as mental rotation. Thus, if the path of motion computed during an apparent motion task is accomplished at a relatively deep level of the perceptual system, it is likely that the path of motion computed during mental rotation is 
done so at a still deeper level of the cognitive system. Whatever processes remain to be done in the mentai rotation task after the stimuli are encoded are what are shared with perceived apparent motion. Therefore if mental rotation tasks and the perception of apparent motion share certain aspects, the perception of apparent movement is analyzed at a deeper cognitive level than real movement.

\section{Using the Same Neural Elements}

On the other side of the argument are those researchers who have argued that the perception of real and apparent motion is processed in the same manner by the nervous system. Uttal (1981) provides one of the strongest arguments against this theory and provides some insight to the whole debate.

Kolers' argument, according to Frisby, can only be considered sound depending on Kolers' interpretation of "mechanism". Though Kolers specified "mechanism" as the nervous system, Frisby does not mention the nervous system. Frisby (1971) and Frisby and Clatsworthy (1973) define "mechanism" in the perception of apparent movement to mean neural elements. His experiments used an adaptation technique: if both real movement and apparent movement are in fact coded by the same movement detecting mechanism, then adaptation caused by a lengthy period of exposure to real movement should affect subsequent 
perception of apparent movement, whereas a carry-over would not be expected if apparent and real movement are coded by quite separate systems. His results affirmed his theory that real and apparent movement are detected by the same neural elements.

One could argue that Frisby's results of carry over from real movement to apparent movement is caused, not because of adaptation in a common movement-detecting "mechanism", but rather because of adaptation caused by both real movement and apparent movement in some earlier "pre-movement" level of the visual pathway. Frisby argues against this by indicating the difficulty in imagining a low level site causing this adaptation and equally not causing an adaptation with either a stationary or flickering light used here as controls, and yet these stimuli did not cause a similar amount of adaptation carry-over shown in the real and apparent movement conditions.

Though Frisby (1971) concluded that there is an overlap in the neural elements used in the perception of real and apparent movement, Uttal (1981) questions the theory that apparent motion produces an internal neural response identical to real motion. In his discussion of neuroreductionism, he compares apparent motion to geometric illusions, which involve higher level interpretation processes rather than isomorphic ones involved by simplistic neuroreductionism. An important implication of this specific result is that no isomorphic neural signal 
need be associated with a perceptual response; symbolic interpretations of suggestive stimuli can suffice to produce a compelling perceptual experience. Identical perceptual experiences can be produced by both isomorphic and nonisomorphic stimuli.

\section{Quality of the Apparent Movement}

Some researchers in the field of motion perception have taken a more moderate approach. They looked at the quality of the apparent movement as a key factor in determining how the information is processed.

Gregory (1966) developed the lock-key theory, he suggested that the visual system will accept stroboscopic movement as a close approximation to real movement, rather as a lock needs to accept a range of slightly varying keys if it is to be of any practical use. He contends that with a modern movie, the resemblance is almost perfect. The lock-and-key theory is easy to believe where movie frames follow each other very closely in space and time: the staircase of tiny steps is a close technical approximation to the smooth ramp of a continuous real movement.

Along the same lines of moderate approaches, Braddick (1974) has put forward the hypothesis that apparent movement is mediated by two processes. He proposes a "short-range" process, which also handles real movement and a "long-range" process, which does not. Braddick's theory is that the short-range 
process is a lock-and-key approximation of real movement perception. The longrange process is thought to respond to stimuli such as a spot that jumps across a large distance -- anything from a $20^{\prime}$ arc to $20^{\circ}$ or more.

In an attempt to understand the perception of movement Julesz (1971) devised random dot stereogram in which both eyes see a random-dot pattern not unlike sandpaper but in the pattern seen by one eye a square central zone has been uniformly displaced sideways by a few dots diameter. When the patterns are fused binocularly in a stereoscope, a central square is seen floating in depth above the plane in the background. Antsis (1970), and Julesz (1971) all presented Julesz's random dot pattern in alternations to the same eye. Both obtained reports of a central random-dot square in apparent motion. Perception of motion here must logically precede the perception of the square form which is created by the movement (Anstis \& Rogers, 1974). This shows that the visual system can compare successive patterns to extract the displacement relationship. Perception of motion here must logically precede the perception of the square form, which is created only by the movement. In this case instead of object identity carrying the motion, it is the motion which defines the square object. The square is invisible in each picture on its own - - there are no correlations within each picture to reveal it: it exists only by virtue of the correlations between the pictures, which the visual system picks up as apparent movement. Any pair of random-dot 
patterns that give depth when presented to each eye in a stereoscope will also give apparant motion when presented to one eye in alternation. Perhaps the neural processing of motion resembles that for depth, except that motion perception must include some short term memory. Antsis argues that there are two different mechanisms for the perception of apparent motion; a short term process, in which motion perception precedes perception and which responds both to apparent and real movement; and a long-range process, in which form perception precedes motion perception and which does not respond to real movement. It makes sense to have a set of hard-wired detectors for real movements that are extremely common visual events. These detectors will accept small displacements on a lockand-key basis. A secondary, global system deals with large displacements which are much rarer events since there are no stroboscopes in nature.

\section{Involvement of the Neural Systems}

Ramachadran and Anastis (1986) further investigated the perception of movement and theorized that the perception of motion may not need any higher level cognitive functions but actually may be analyzed by the visual apparatus. The evidence of their study indicates that in perceiving motion a viewers' visual system rapidly extracts salient features and applies built-in laws of motion when processing the features. The experiments that they conducted flashed images too rapidly to allow the brain to make thoughtful decisions about 
what it was seeing. Their results suggested that low-level processes can, on their own, control the perception of apparent motion during the early stages of visual processing.

\section{Brain Activity and Electroencephalograms}

Cortical Areas Involved in the Perception of Movement

Research with monkeys has shown that the visual cortex is not the only area of the brain necessary to detect movement (Milner, 1970, p. 205). Monkeys with ablation of the visual cortex were still capable of detecting whether a stimulus was moving or stationary. Further investigation with individuals who suffered brain trauma has also supported the hypothesis that the visual cortex is not all that is necessary for making discrimination based on movement. Therefore which areas of the visual apparatus are responsible for the detection of movement?

\section{Electroencephalography and the Perception of Movement}

Electroencephalograms have been widely used to determine underlying cortical activity as it relates to perception. Using EEGs many of the researchers have used the event related potential (ERP) method. The ERP method consists of multiple overlapping component waves, where each component is considered 
to be associated with an elementary brain response. A component wave is a time dependent fluctuation of the corticoelectrical potential, that has a distinct peak amplitude, and occurs at a distinct latency after stimulus onset and at a distinct location on the scalp (Fabiani, Gratton, Karris \& Donchin, 1987). While there is a need for caution in accepting claims that perceptual and cognitive processes have specific effects on evoked response configurations, it does seem clear that mid-latency evoked response components are related in some way to the processing of sensory input. This is particularly evident when the topographic distributions of evoked potential components over the scalp are examined (Niedermeyer \& de Silva, 1982, p. 458).

\section{Electrical Brain Activity During Visual Tasks}

Rebert, Low and Larsen, (1984) examined the differential hemispheric activation during complex visuomotor performance: alpha and theta rhythms. The alpha rhythm is the most frequent feature of the EEG in a normal, awake adult. A sensory stimulation will cause the disappearance of the alpha rhythm and its replacement by a lower voltage faster frequency. While automatic analysis has demonstrated that a small amount of theta activity is always present in the EEG of a normal, awake adult, the presence of this frequency in discernible amount in the visually analyzed record is usually taken as an indication either of drowsiness, sleep, or of an abnormality in brain function (Niedermeyer \& Da 
Silva, 1982). Rebert et al. (1984) were able to find significant differences in the localizations of brain activity. The alpha power was stable in the left hemisphere but decreased in the right hemisphere during a complex visuomotor activity. Theta activity increased bilaterally in most of the tasks, either verbal, nonverbal, or visuomotor, and differed from the alpha patterns in several respects. This indicates that the right hemisphere is more adapt than the left in the processing of visuospatial information. Their study showed the importance of electroencephalograms in the study of processing visuospatial information.

Rhythmic alpha activity in the range of $8-13$ hertz is evident in the normal adult human EEG recorded from the posterior regions of the scalp, whereas lowvoltage irregular "faster" activity (in the range of 14-40 hertz, approximately) predominates anteriorly, at times with some admixed activity in the alpha and theta frequency ranges. Low-voltage irregular activity anteriorly can be taken to reflect a continuously "active" prefrontal cortex, with extensive interconnections with other cortical areas. Rhythmic alpha posteriorly may be taken to be a reflection of an "idling" posterior cortex (Barlow, 1993).

Usually visual perception, mental imagery and attention are associated with varying degrees of alpha blocking, sometimes together with either suppressed or augmented beta rhythms, and/or augmented theta rhythms (Mundy-Castle, 1951). Some variation in the EEG during mental activity include alpha blocking, 
selectively attenuated alphoid rhythm from temporal areas (Gastaut, 1951) and augmented theta rhythm (Mundy-Castle 1951; Brazier \& Casby, 1952). MundyCastle, (1957) in the study of mental activity using EEG was able to conclude that the alpha rhythm is very much concerned with visual processes. Maximal blocking of the alpha rhythm is far greater with eyes open than with mental activity, and during mental activity, far greater with visual imagery and mental arithmetic than with auditory or kinesthetic imagery.

Mariko Osaka (1984) investigated the effect of task difficulty on the alpha rhythms; bilateral EEGs were recorded from both the frontal and the occipital areas from 10 subjects who were engaged in either an arithmetic or visual-spatial task. Knott (1938) and Hadley (1941) had reported that the frequency of the alpha rhythm increased toward a higher frequency region during mental tasks. Osaka (1984) was able to conclude that peak alpha frequencies increase during both arithmetic and visuo-spatial tasks. Furthermore, the shift towards higher frequency within the alpha band increases as task difficulty increases.

The alpha rhythm has also been examined in comparing neurophysiological difference between perception and imagery. The alpha power was increased over the whole scalp during imagery in comparisons to perception. Further the alpha power showed frontal-central activity. The perception of a visual stimulus depressed the alpha power uniformly over the scalp (Schupp, Lutzenberger, 
Birbuamer, Miltner, \& Braun, 1994).

Visual perception, mental imagery, and attention are usually associated with varying degrees of alpha blocking, sometimes together with augmented theta rhythms (Mundy-Castle, 1951), there may be both similarities and differences in the patterns of alpha and theta activities as a function of task. Rebert, Low, and Larsen (1984) in examining hemispheric activation during complex visuomotor performance found that alpha and theta were similar in exhibiting a reversal of asymmetry in verbal and nonverbal tasks. Their results are also compatible with the notion that some generators of theta activity are involved in attention or motor control. Further, they suggest a more general role of theta in attentional processes.

\section{Cortical Areas Responsible for the Perception of Movement}

Eals (1987), defines the perception of movement as a spatial process. Movement perception requires first an appreciation of an initial spatial array, then an appreciation of a temporally changed locus of the array in relation to the initial perception. Further, based on the finding that selective disturbances of movement vision can occur after bilateral cerebral damage, it has been suggested that movement perception is a separate visual function. Eals suggests that the hemispheres may be involved differently in this function. He showed that when dot arrays are tachistoscopically presented to the visual half-fields, response 
accuracy was greater for stimuli presented to the left field than for identical mirror-image stimuli presented to the right field. The left visual field superiority confirms that the right hemisphere is, to some degree, specialized for the processing of this type of spatial information, indicating that there can be a hemisphere difference in the perception of movement.

If the perception of apparent movement uses different brain activities than the perception of real movement and is similar to more complex visual-spatial tasks, anterior cortical areas could be activated. Frontal lesion in human subjects has been associated with decreases in spatial working memory capacity (Owen, Downes, Sahakian, Polkey, \& Robbins, 1990). Functional magnetic resonance imaging localized spatial working memory in humans to the middle frontal gyrus area (McCarthy, Blamire, Puce, Nobre, Bloch, Hyder, Goldman-Rakic, Shulman, 1994). Another study using positron emission tomography (PET) studied the regional cerebral blood flows in normal humans and revealed activation in righthemisphere prefrontal, occipital, parietal and premotor cortices accompanying spatial working memory processes (Jonides, Smith, Koeppe, Awh, Minoshima, \& Mintun, 1993). 


\section{Summary of the Chapter}

The neural elements involved in the perception of apparent motion versus real motion have been debated since the nineteen sixties. Several theories have been proposed on the neural elements involved in perceiving motion. Kolers (1963) suggests that different neural elements are involved in perceiving apparent movement as opposed to real movement. Frisby (1973) has argued against this view and has attempted to demonstrate that the same neural elements are used in both types of perception. Still others such as Gregory (1966) and Braddick (1974) have suggested that it is the quality of the apparent movement that determines how the visual system handles the stimuli and processes the information.

EEGs have been used in various experiments in visual perception and can be used to examine the cortical activity which is occurring during the perception of real and apparent movement. Both the theta and alpha rhythms have been shown to be related to the visual system and visual perception, and associated with attention demands and degree of difficulty of the tasks. The frontal area of the brain seems to be related to visual processing as well as to spatial working memory. Further, there appear to be hemispheric differences related in visual tasks.

EEG technology can be used to study the visual perception of real and 
apparent movement. From the previous research both theta and alpha rhythms should be considered and both occipital and frontal areas of the brain should be analyzed carefully. 


\section{Research Methodology}

\section{Statement of Problem}

This study is concerned with the following question: is there a difference in brain activity, measured by quantified electroencephalography, between perceiving apparent movement and real movement when the stimuli are presented in a computerized environment?

\section{EEG and The Perception of Movement}

Koler (1963) suggested that different neural elements are involved in perceiving apparent and real movement. Frisby (1973) has argued against this view and has attempted to demonstrate that the same neural elements are used in both types of perception. Others such as Gregory (1966) and Braddick (1974) have suggested that the quality of apparent movement determines how the visual system handles the stimuli and processes the information.

Electroencephalograms have been used in various experiments in visual perception (Fabiani, Gratton, Karris \& Donchin, 1987; Rebert, Low \& Larsen, 1984) and can be used to determine the cortical activity that occurs during the perception of real versus apparent movement. Researchers have been able to relate both the theta and alpha rhythms to the visual system and to visual perceptions (Brazier \& Casby, 1952; Barlow, 1993; Gastaut, 1950; Osaka, 1984; Mundy-Castle, 1951; Mundy-Castle, 1957). The frontal area of the brain seems to be related to visual processing as well as spatial, working memory (Jonides, 
Smith, Koeppe, Awh, Minoshima, \& Mintun, 1993; McCarthy, Blamire, Puce,

Nobre, Bloch, Hyder, Goldman-Rakic, Schulman, 1994; Owen, Downes,

Sahakian, Polkey, \& Robbins, 1990).

Based on this evidence the following hypotheses were developed:

Hypothesis 1:

There will be no significant differences in alpha rhythms in the frontal areas of the brain between seeing two flashing lig, ics at two distinct places and seeing flashing lights perceived as moving.

Hypothesis 2:

There will be no significant differences in theta rhythms in the frontal areas of the brain between seeing two flashing lights at two distinct places and seeing flashing lights perceived as moving.

Hypothesis 3:

There will be no significant differences in alpha rhythms in the occipital areas of the brain between seeing two flashing lights at two distinct places and seeing flashing lights perceived as moving.

Hypothesis 4:

There will be no significant differences in theta rhythms in the occipital areas of the brain between seeing two flashing lights at two distinct places and seeing flashing lights perceived as moving. 
Hypothesis 5:

There will be no significant differences in alpha rhythms in the frontal areas of the brain between seeing flashing lights perceived as moving and seeing real movement.

Hypothesis 6:

There will be no significant differences in theta rhythms in the frontal areas of the brain between seeing flashing lights perceived as moving and seeing real movement.

Hypothesis 7:

There will be no significant differences in alpha rhythms in the occipital areas of the brain between seeing flashing lights perceived as moving and seeing real movement.

Hypothesis 8:

There will be no significant differences in theta rhythms in the occipital areas of the brain between seeing flashing lights perceived as moving and seeing real movement.

\section{Subjects}

Recent findings in neuroscience indicate the occurrence of synaptic and dendritic growth spurts in different areas of the brain which may be related to qualitative changes in cognitive behaviour (Fischer, 1987; Huttenenlocher, 1979, 1990). Stauder, Molenarr, Maurits, and Molen (1993) found evoked related 
potential (ERP) differences in children who were in either unservers or nonconservers as described by Piaget. To avoid any developmental issues as they are related to brain activity, subjects for this study were all adults over nineteen years of age.

Previous research has found that the EEGs of adults over sixty years of age demonstrate an alpha rhythm which decreases in frequency, prominence, and reactivity. Beta activity is often more prominent, and sporadic, generalized slow waves may be slightly more common than in younger adults (Fisch, 1991). Researchers have also found a correlation between the threshold of motion perception and age (Gilmore, Wenk, Naylor,\& Stuve, 1992). Therefore to ensure homogeneity, all subjects in the present study were under the age of sixty.

The experiment involved a sample of 11 subjects between the ages of 19 years - 4 months and 44 years - 11 months, with a mean age of 24.5 years. Four of the subjects were men and seven were women. All the subjects were volunteers from McGill University undergraduate or graduate programs. All the subjects were considered normal and did not report any medical problems. Ten subjects reported no use of medication in the previous 24 hours; one subject reported taking Attarax (antihistamines) for her allergy. None of the subjects reported taking illegal drugs or alcohol in the previous 24 to 48 hours. 


\section{Presentation of Stimuli}

All stimuli were presented in a computerized environment. The computer used for the stimuli presentation was a QSI 9000 Data Analysis Work Station. It had a 80386,32 bit microprocessor and a 80387 mathematical co-processor, with 2 megabytes of random access memory and a 20 megabyte hard drive. It also had a VGA graphic processor. All the stimuli were presented on its $13^{\prime \prime}$ high resolution colour monitor.

\section{Description of stimuli}

All the stimuli were created using The Animation Studio software (Walt Disney Company, 1991). There were four different conditions. In each condition the stimuli consisted of a circular shape, $1 \mathrm{~cm}$ in diameter. The circular shape was white presented on a black background.

Each condition was presented at three different speeds, 1, 5, and 12 frames per second. The stimuli moved across the computer screen from left to right in a straight line.

A frame was defined conceptually as a single still frame in movie film. There are usually 24 frames per second in conventional film making, which means that 24 frames are projected every second. The frame rates chosen were all below 24 frames per second since at this speed most stimuli would be perceived as 
moving and the threshold of perceived movement would be difficult to ascertain. To increase the time interval between circular objects and to maintain the same speed, blank frames were included.

In the first condition, the stimulus appeared at two distinct locations on the computer screen without producing the perception of apparent movement. The two circular objects appeared $12 \mathrm{~cm}$ apart with 5 blank frames between each object presentation. At 1 frame per second the first circular object appeared for 1 second and 5 seconds later the second circular object appeared for 1 second. At 5 frames per second the first circular object appeared for 200 msecs and 1 second later the second circular object appeared for 200 msecs. At 12 frames per second the first circular object appeared for 83 msecs and 417 msecs later the second circular object appeared for 83 msecs. There was a total of 11 frames.

In the second condition the stimulus appeared at eight distinct places, 1.5 cm apart, with four blank frames between each object presentation, and was developed to produce the perception of a broken or non-continuous moving object. At 1 frame per second the first stimuli would appear for 1 second and 4 seconds later the second circular object would appear for 1 second. At five frames per second the first circular object would appear for 200 msecs and 800 msecs later the second circular object would appear for 200 msecs. At 12 frames per second the first circular object would appear for 83 msecs and 334 msecs later the 
second circular object would appear for 83 msecs. There was a total of 40 frames. In all cases this occurred eight times until the object reached the far right of the computer screen.

In the third condition a stimulus was developed to produce the perception of movement. The circular objects were $1.5 \mathrm{~cm}$ apart but no blank frames were inserted among them. At a frame per second the first circular object would appear for 1 second and immediately after the second circular object would appear 1.5 $\mathrm{cm}$ apart for $\mathrm{l}$ second. This produced a shadowing effect (non-overlapped), where subjects would report seeing the first stimulus fade as the second appeared. At 5 frames per second the circular objects were presented for 200 msecs, and at 12 frames per second the circular object were presented for 82 msecs. There was no time interval between objects and there was a total of 8 frames.

In the fourth condition a stimulus was developed to produce continuous smooth movement, with overlapping and a blurring effect. The circular objects were redrawn on the screen offset by $7 \mathrm{~mm}$, thereby appearing to move $3 \mathrm{~mm}$ to the right per frame presentation. This overlapping caused blurring of the previous object as the next object was seen. At one frame per second each circular object was presented for 1 second, at 5 frames per second each circular object was presented for 200 msecs, and at 12 frames per second each object was presented at 83 msecs, without any time interval between objects. There were 76 frames in 
total.

Each condition was presented for a 3 minute duration. As the circular object reached the far right of the screen it would "wrap around " or reappear on the left side with the same time interval maintained throughout the presentation. The circular object was usually referred to as a flashing light by the subjects.

\section{The Electrophysiological Monitoring System}

As the subjects were looking at various stimuli they were monitored on a computer-based electrophysiological system, the QSI 9000, used to record and analyze the EEG data. The QSI 9000 system allows for the acquisition and storage of 20 channels of EEG data. These data can be displayed on a high resolution graphics monitor, simulating the output of conventional EEG devices.

Individual 2.5 second epochs or segments of EEG were selected for Fast Fourier Transform (FFT) analysis. This transformed the raw EEG data into numerical values which could be displayed or utilized to display a table of means and standard deviations for each of the power bands, a histogram in a vertical bar graph, or an averaged spectral distribution indicating the individual frequency components. Further, these numerical values could also be converted into twodimensional coloured topographic maps of the EEG activity in all regions of the brain for each frequency band. 
A useful purpose of quantified electroencephalography is the comparison of numerically transformed data to a normative database of medically-healthy, age-matched individuals. The QSI 9000 has an extensive database from 6 to 79 years. Above the age of 20 , subjects are grouped by decade. There are no separate groupings by gender as electrophysiological differences between men and women are minimal (Coffin, 1992).

\section{Procedure}

The purpose of this study was to examine the brain activity of normal adult subjects as they perceived movement or the lack of it. Subjects served as their own controls. Two baseline measures were included: eyes open looking at a computer screen and eyes closed at rest. The eyes closed at rest recording was used to compare subjects with a normative data base to ensure all subjects were within a normal range of brain activity and did not have any apparent neurological abnormalities. The eyes open recording was used to compare the differences, if any, between looking at a static computer screen and perceiving movement on the screen. The four different conditions were then presented. The subjects viewed real movement, a close approximation of movement, flashing lights presented in such a manner as to produce the perception of movement, and two flashing lights which did not produce the perception of movement. All the 
stimuli were presented in a computerized environment.

The subjects were explained the procedure and were asked to sign a consent form (see Appendix C). The subjects were seated approximately 20 to 22 inches from the computer screen, depending on what they perceived to be more comfortable. The room was dark during the presentation of the stimuli. During a pilot study it was found that maximal stimulation for the optical area of the brain was achieved in a dark room with the stimulus being white on a black background.

Subjects were told that after viewing a stimulus, they would be asked to report what they saw. They should report if the object moved, or if the object was in movement, and any other information they thought was pertinent. Their responses were recorded by the experimenter for each stimulus.

Each stimulus at the three different frame per second rates was presented for 3 minutes, during which the subjects' EEG was being recorded in separate files. After the 3 minute presentation the subjects were asked to report what they saw.

\section{EEG Recordings}

The EEG recordings were made on the QSI model 9000 and monitored on its screen. In order to compare the files to the normative data base the QSI 9000 default parameters were modified, the default filter was kept for a bandpass of 
$.05-30 \mathrm{hz}$ and the sampling time was modified to 4.88 milliseconds. Since the electrical signal output by the brain is relatively low voltage, it is necessary to use 20 differential amplifiers to augment the signal for recording purposes. The number of times the signal is amplified or increased is referred to as an amplifier gain. The recording amplifiers are conventionally set using a constant gain of $80 \mathrm{~K}$ (Coffin, 1992). Records with eye movement and EEG fluctuations exceeding $70 \mu \mathrm{V}$ were excluded from further analysis.

The 20 gold plated electrodes were placed according to the International 10/20 system configuration (Appendix A). Preparation time including the measurement of the head and the placement of the electrodes took approximately 40 minutes.

Electrode impedances are normally measured after an electrode has been applied to the recording site to evaluate the contact between electrode and scalp. The impedance of each electrode should be measured routinely before every EEG recording and should be between $100 \mathrm{ohms}$ and $5000 \mathrm{Ohms}$ (Fisch, 1991). For this study the impedance was checked routinely before each EEG recording and impedance values of 900 ohms or below were obtained.

\section{Recording Montages}

The EEG recording, with the QSI 9000 , is a referential montage with a 
linked ear reference. The EEG records variations of brain activity and is actually a recording of the electrical potential differences between pairs of electrodes. In a referential montage each scalp or "active" electrode is compared to a common reference, usually a neutral, extra-cerebral electrode (Fisch, 1991). Typically, linked ears (both ears used as extra-cerebral electrode) is the most commonly used reference and this is the default recording montage for the QSI 9000 .

\section{Artifact Rejection}

Artifacts are recordings that are not due to cerebral activity and may come from such extracerebral activity as eye movements, heart beats and muscle contractions or from electrical interference, malfunctioning recording electrodes, or defects of the EEG machine. They must be eliminated or clearly explained to avoid confusion with cerebral activity (Fisch, 1991).

The artifact rejection was done manually prior to analysis on the QSI 9000. The process of "artifacting" involved the rejection by visual inspection of those segments of the EEG which contained artifacts from the EEG record. These artifacted segments were properly marked and the QSI 9000 eliminated them from the analysis of the records. The 3 minute recording in each condition was artifacted in such a manner as to keep the clearest 1 minute of the recording for use in the subsequent analyses. 
Description of the Electrophysiological Measures

The data, once edited for artifact, were subjected to a FFT in order to convert the raw EEG data into numerical values. 'The EEG frequency spectrum is conventionally broken down into four major frequency bands: delta (0.4 - 3.6 $\mathrm{Hz})$, theta $(4-7.6 \mathrm{~Hz})$, alpha $(8-12.6 \mathrm{~Hz})$, and beta $(13+\mathrm{Hz})$. Absolute power refers to the average expression of magnitude of the electrical signal in each of the frequency bands, based on constant gain from all recording amplifiers. Absolute power was used in all cases and was derived directly from the power spectrum, grouped by frequency band.

\section{Summary of the Chapter}

The study is concerned with differences in brain activity, measured by quantified electroencephalography, when perceiving apparent versus real movement. The hypotheses were developed to consider any differences in alpha and theta rhythms, in both the frontal and the occipital areas of the brain, before seeing movement, when the perception of movement occurred, and seeing real movement.

The subjects involved were all university students who had volunteered for the experiment. The mean age of the subjects was 24.5 years. All were considered normal with no indications of neurological problems. 
All the conditions were generated by animation software and were presented on a computer screen. Four different conditions were developed and presented at three different speeds of projection.

Subjects were asked to look at the stimuli and try to keep their eyes still while their brain activity was monitored on a computer-based electrophysical system, the QSI 9000 . All subjects were seated in a dark room, and after each stimulus presentation of a white circular on a black background, the subjects were asked to report what they had seen.

All EEG records were artifacted to delete the interference from the record. The clearest 1 minute of the record was kept for later analysis. The raw EEG was then subjected to a Fast Fourier Transform, in order to convert the raw EEG data into numerical values. Only absolute power was used for analysis. 


\section{Results}

This chapter presents the results of the data analyses. All hypotheses were tested using statistical analyses of the numerically transformed EEG data. After visual inspection of the topographic brain maps, qualitative analyses were performed.

\section{Analyses of Data}

A Fast Fourier-based analysis transformed all the EEG records into numerical values. These numerical values formed the bases of later statistical analyses and were also utilized to generate the topographic brain maps.

Relative power is defined as the proportion of electrical activity in each frequency band relative to the total power. The extensive eye movement caused substantial increases in delta power thereby increasing total frontal power. Increases in theta power correlated with the experimental conditions were not due to residual eye movement in the record since the theta power was larger around the $\mathrm{CZ}$ rather than $\mathrm{FZ}$ location, and larger at the $\mathrm{FZ}$ rather than the Fpl and Fp2 location fur four of the six subjects. Theta generated by eye movement would have been greatest around the $\mathrm{Fpl}$ and $\mathrm{Fp} 2$ location and greater at the $\mathrm{FZ}$ rather than $\mathrm{CZ}$ location. Since relative power could have distorted total power in the frontal areas which are of interest in this study, it was decided to analyze only absolute power.

Though 20 electrodes were utilized in the EEG recordings only frontal and 
occipital electrodes were used for the analyses. For the statistical analyses, paired $t$-tests were conducted. The conventional significance level of $p\langle .05$ was utilized. For the frontal area all numerical values of the seven electrodes (Fp1, Fp2, F3, F4, F7, F8, Fz) associated with this area were grouped together. For the occipital area numerical values of the two electrodes $(\mathrm{O} 1, \mathrm{O} 2)$ associated with this area were grouped together. The total numerical value (see Appendix B) for each electrode was used to obtain the mean, mean difference and the standard deviation in the correlated $t$-tests. The correlated $t$-tests were used to compare means from the same subject under different experimental conditions. For each subject, each condition compared was at the same frame rate of presentation. Since different frame rates of presentation causes perception of different rates of speed for the stimulus, to control this possible confounding variable, a constant frame rate was used.

The topographic brain maps were generated from the Fast Fourier Transformed numerical values using the analysis mo: 11 : of the QSI 9000. Further, all subjects were compared to the normative data base which resides in the QSI 9000. z-score differences for the eyes-closed condition, comparing each subject to the normative data base were computed for each electrode reading.

All the topographic brain maps used the absolute colour scale. An absolute 
power map produces the actual microvoltage squared, representing each of the four physiological frequency bands across all twenty electrode leads. The colour scale of the absolute power has a black background with increased activity represented as a darkening of colour from white to dark red (see Figure 1).

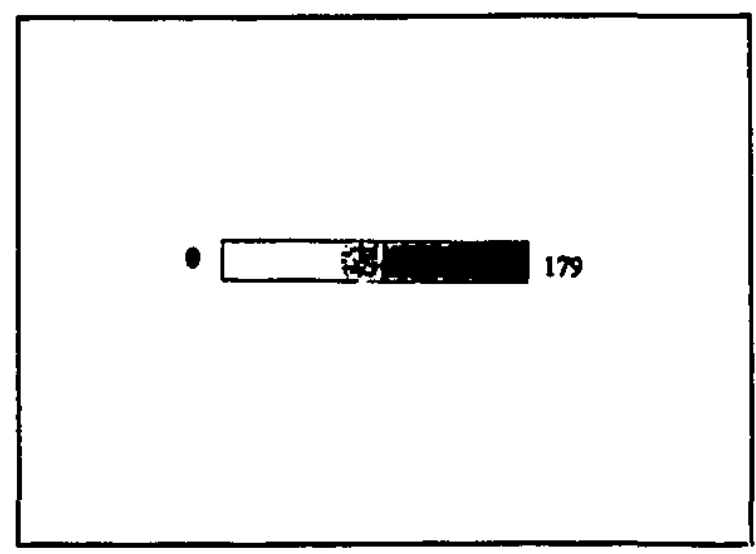

Figure 1 - Colour scale

\section{Analysis of the Resting EEG}

The eyes-closed at rest recording for each subject was compared to the normative data base of medically healthy individuals. All subjects were compared to individuals within their age group. $z$-score differences were obtained for all electrodes. Any individual within two standard deviations of the normative data base was considered normal.

Using this criteria, 7 of the 11 subjects were within the normal range. One subject had a significant increase in the left temporal area of alpha power when 
compared to the normative data base. Another had a significant decrease in delta power in the frontal and right occipital areas, as well as significant differences in theta and alpha power. Still another subject had a significant increase of theta power in the temporal, midline frontal, and occipital regions when compared to the normative data base. A significant difference in the delta power in the temporal regions was also apparent. All differences were found to be between \pm 2.33 and \pm 3.02 standard deviations from the mean. The final subject had a significant increase in the theta power in the frontal areas, between 3 and 4 standard deviations above the mean. Since these subjects showed significant differences compared to the normative data they were excluded from the final analysis, even though they did not appear to have any major neurological problems. Their exclusion caused only negligible differences in the final analysis. In addition to the above, of the 11 subjects, one female subject was also excluded from the final analysis. She did not report perceiving movement until the final condition. Because she reported the perception of movement only when in the real movement condition, it was not possible to determine her threshold for apparent movement.

In the final analyses six subjects were examined. Three of the subjects were men and three were women. 


\section{General Overview}

In an effort to simplify the results a general presentation of the results is required. There were four conditions, eyes-open, a flashing circular object, and the subject's reported threshold of movement and real movement. All the conditions were compared to each other. The complexity of the stimulus increased in each of these conditions, from none to overlapping circular objects with a shadowing effect.

After having examined closely the eyes-open to the other conditions a general increase in frontal alpha was detected. There was also a general trend for frontal theta to increase. In each condition it was the same two subjects who had a constant decrease in theta. One of these subjects did not have a significant decrease in theta when comparing eyes-open to their reported threshold. Some subjects did not have a significant difference until they perceived real movement. There were almost no changes in the occipital areas when comparing the various conditions. A graph of the subjects who exhibited significant differences is presented in Figure 2. 


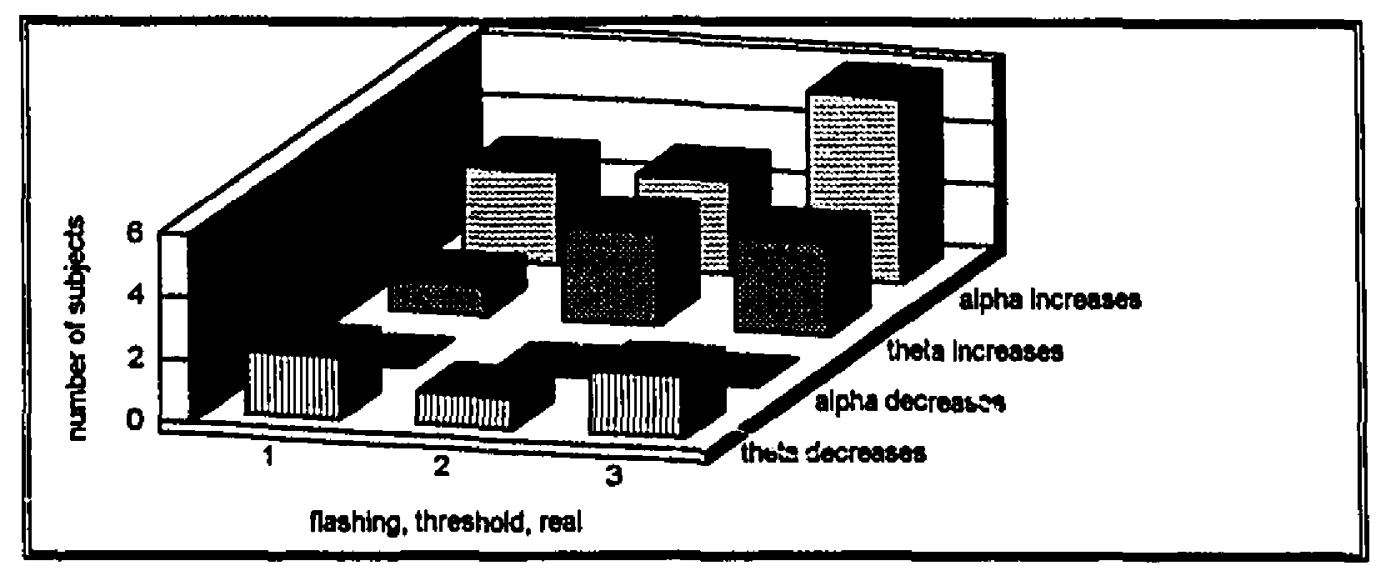

Figure 2

Eyes-open compared to the three experimental conditions.

Changes in frontal alpha and theta

In the next level of complexity among the different conditions-comparing a flashing circular object, the reported threshold of movement and real movement, again there was a tendency for both frontal alpha and theta to increase. Some subjects did not have significant differences. Further, there was a tendency for both alpha and theta to change in the same direction when comparing the flashing object to real movement. There were very few significant changes in the occipital areas in the comparisons of the various conditions. A graph of the subjects who 
exhibited significant differences is presented in Figure 3.

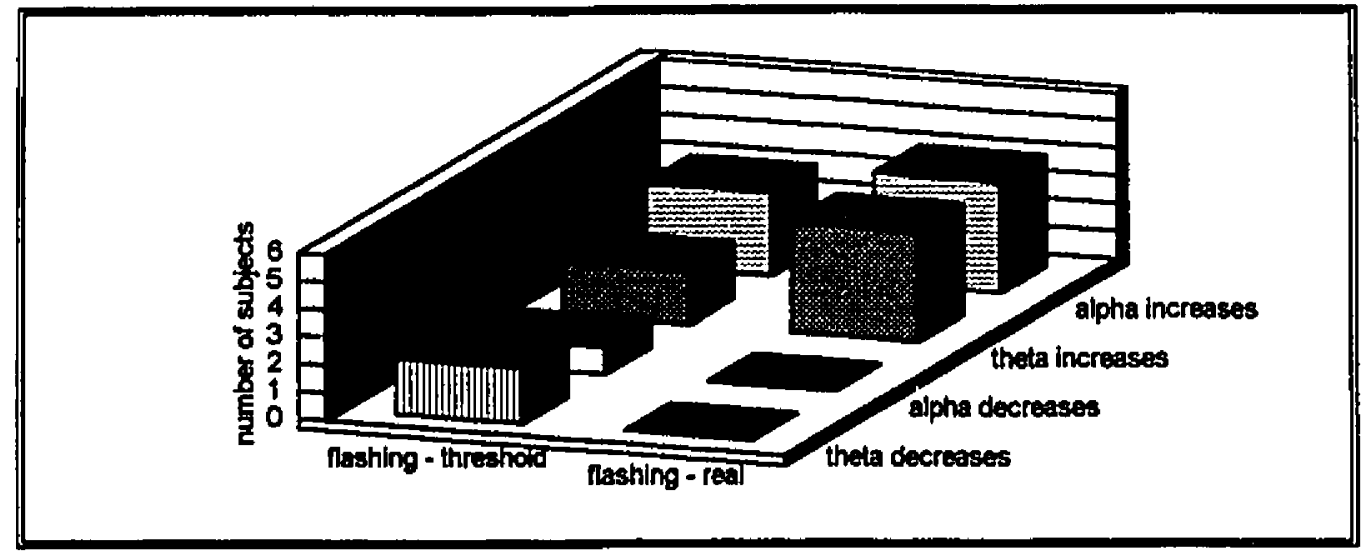

Figure 3

Comparison of seeing a flashing object to the threshold of movement and real movement.

Changes in frontal alpha and theta

In the comparison of the two most complex conditions -- comparing the reported threshold of movement with real movement, there was a general tendency towards an increase in frontal alpha. Also the changes in frontal alpha and theta are generally in the same direction. Some of the subjects did not have significant differences. There were few significant changes in the occipital areas. A graph of the subjects who exhibited 
significant changes is presented in Figure 4.

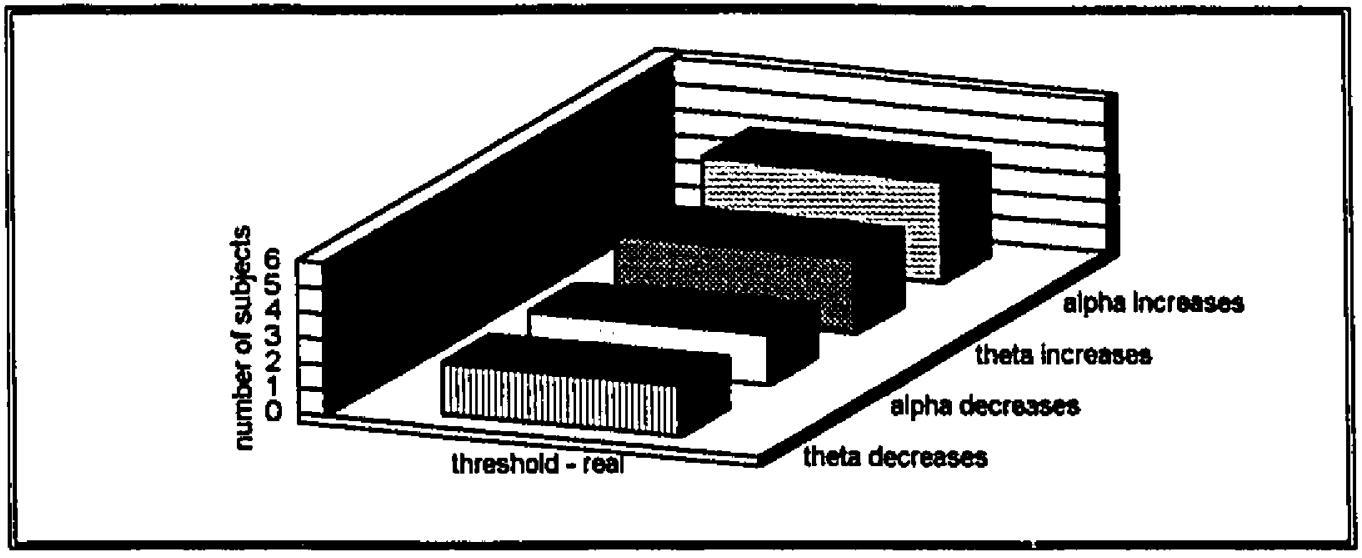

Figure 4

The threshold of movement compared to real movement.

Changes in frontal alpha and theta

Where there were statistically significant changes there was an increase of frontal alpha from the least to most complex condition. Frontal theta seemed to follow the same directional change of frontal alpha but there were some individual differences.

Inspection of the brain topographic maps revealed some general information. Frontal alpha power peaked for two of the six subjects at the reported threshold of perceived movement while two peaked at real movement 
and for two no peaks were observable. Frontal theta power peaked for two of the six subjects at the reported threshold of perceived movement while one had a peak at real movement. Many of the apparent changes on the topographic brain maps in the alpha and theta power were in the central (CZ) to mid frontal (FZ) (see Appendix A); this awaits further evaluation. Also there were apparent lateralized differences in occipital alpha which can be explained by subjects moving or tilting their heads while viewing the stimuli (see Figures 5-10).

Since occipital alpha, which is usually maximal at the occipital area with eyes closed, is typically more anterior with eyes open as can be seen in the topographic maps (see Figures 5-10), it was decided to analyze the absolute alpha power in the parietal area ( P3, PZ, P4). 


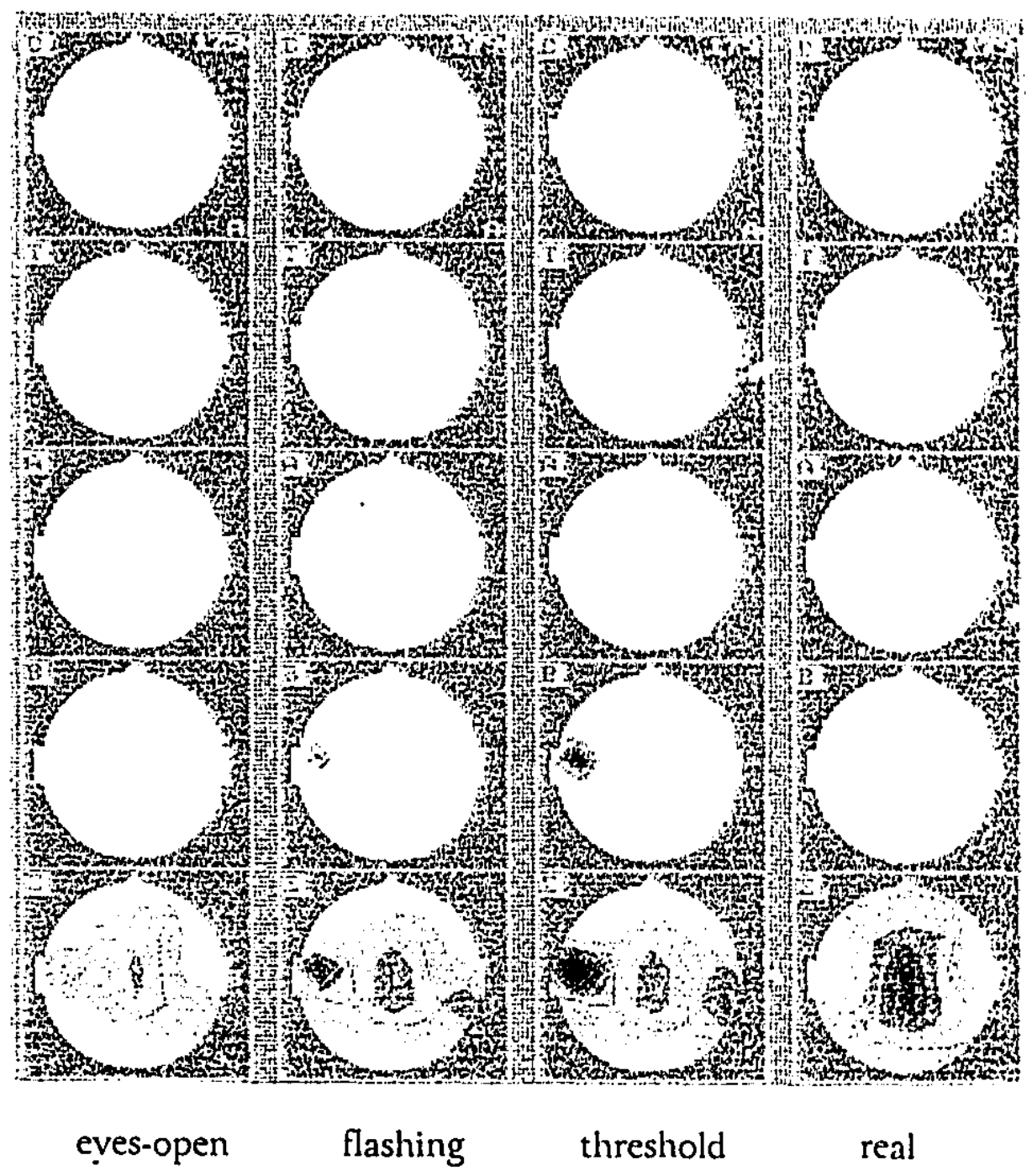

Figure 5

TOPOGRAPHIC BRAIN MAP OF SUBJECT \# I 


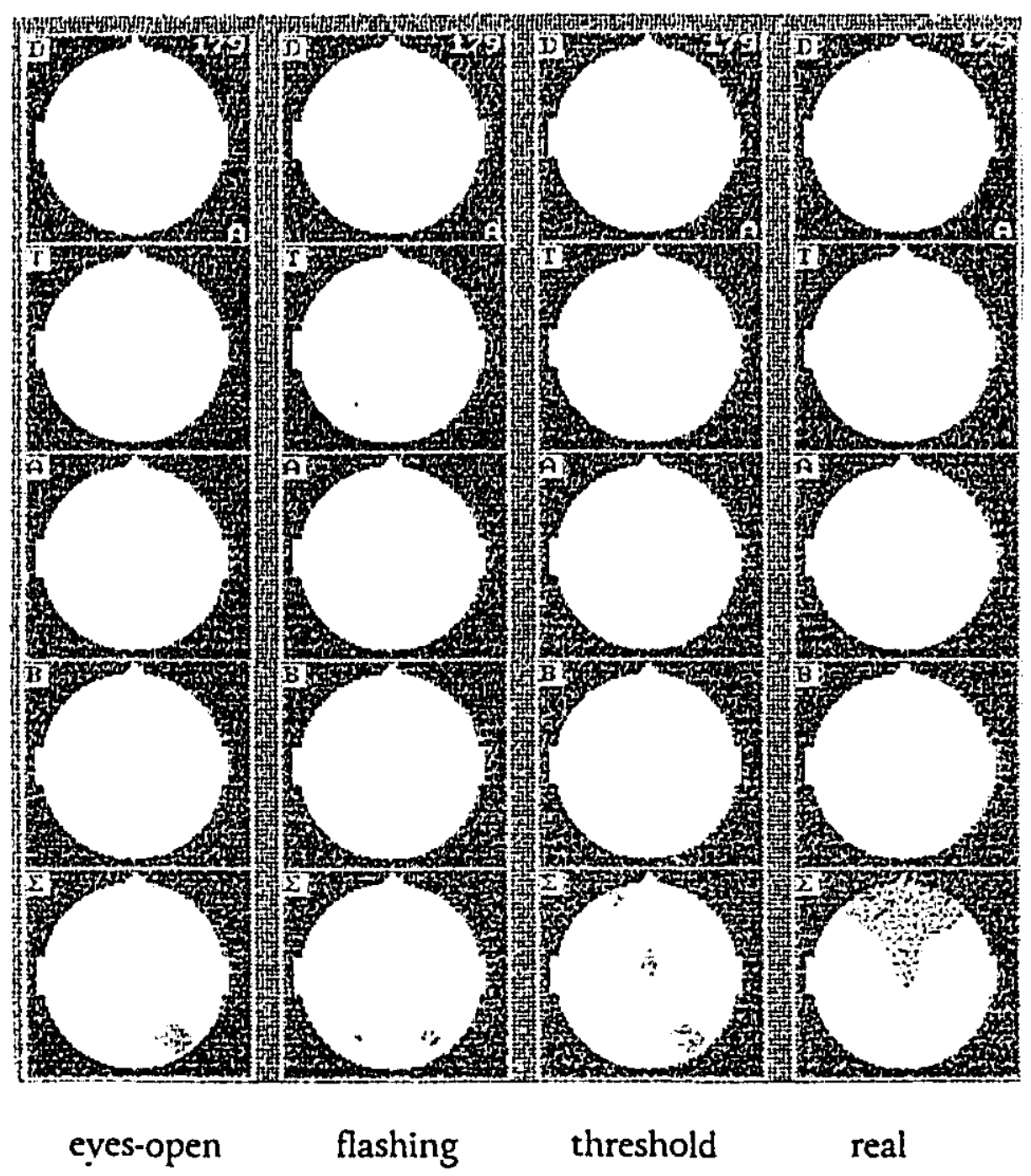

Figure 6

TOPOGRAPHIC BRAIN MAP OF SUBJECT \# 2 


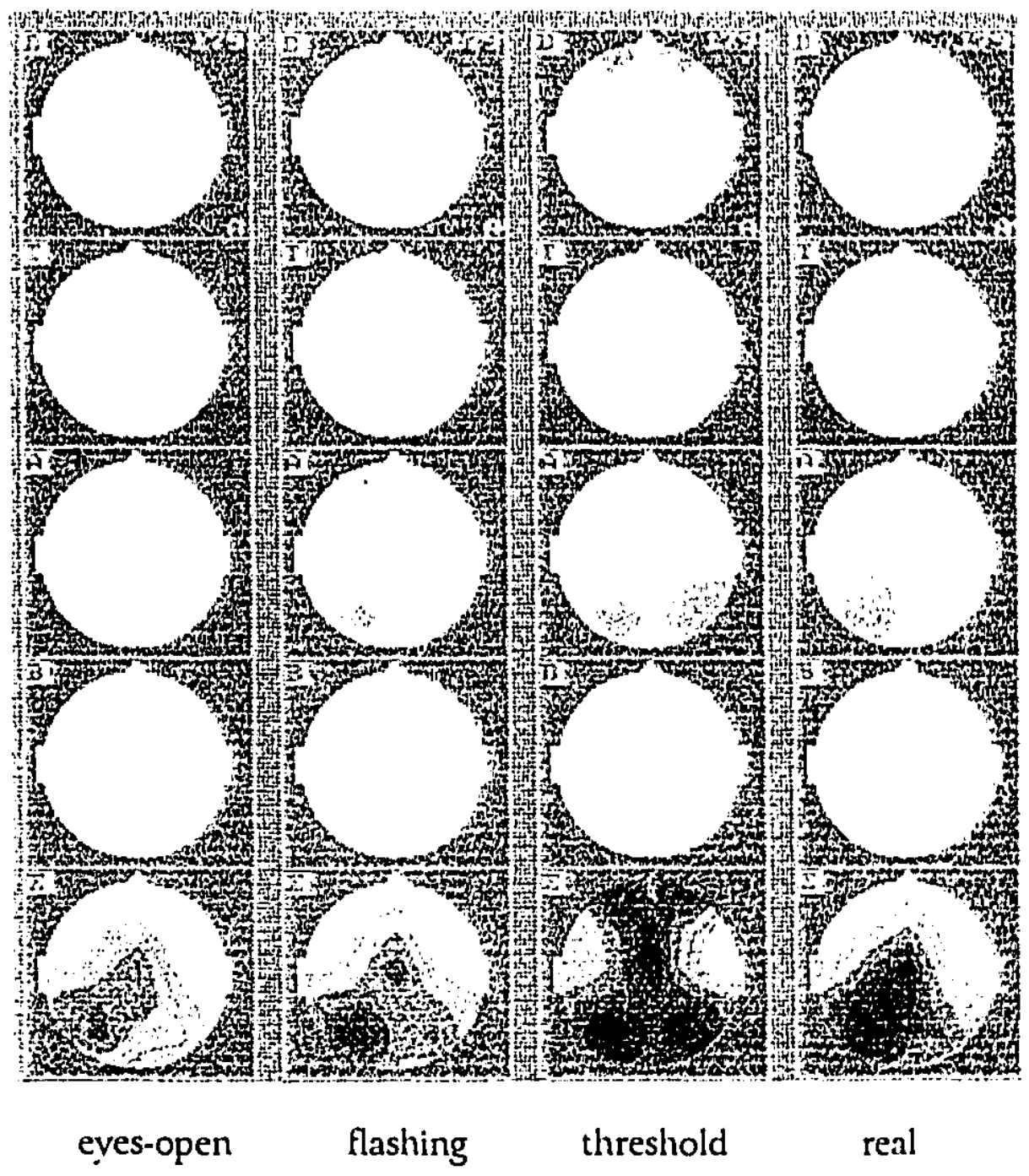

Figure 7

TOPOGRAPHIC BRAIN MAP OF SUBJECT \# 3 


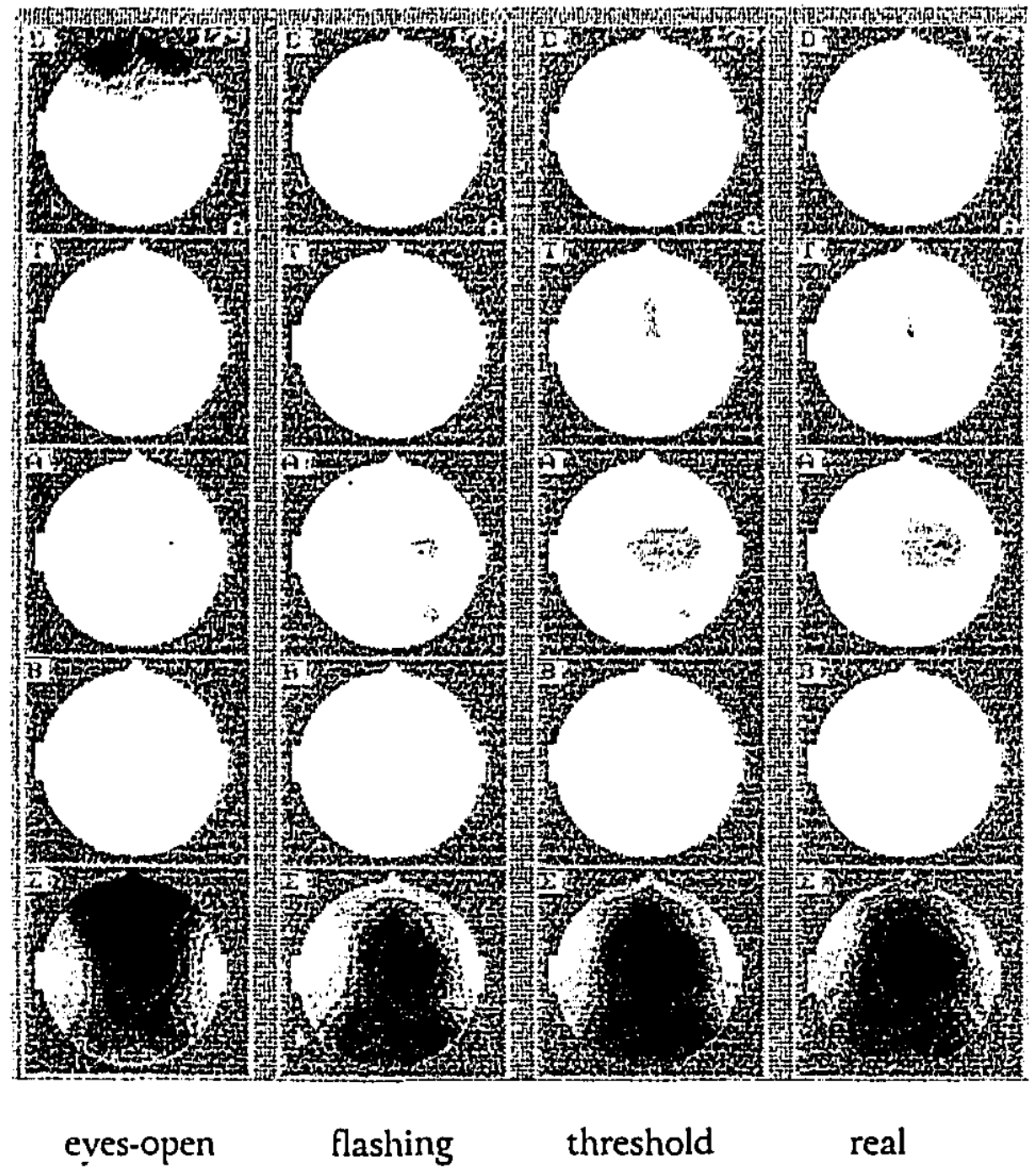

Figure 8

TOPOGRAPHIC BRAIN MAP OF SUBJECT \# 4 


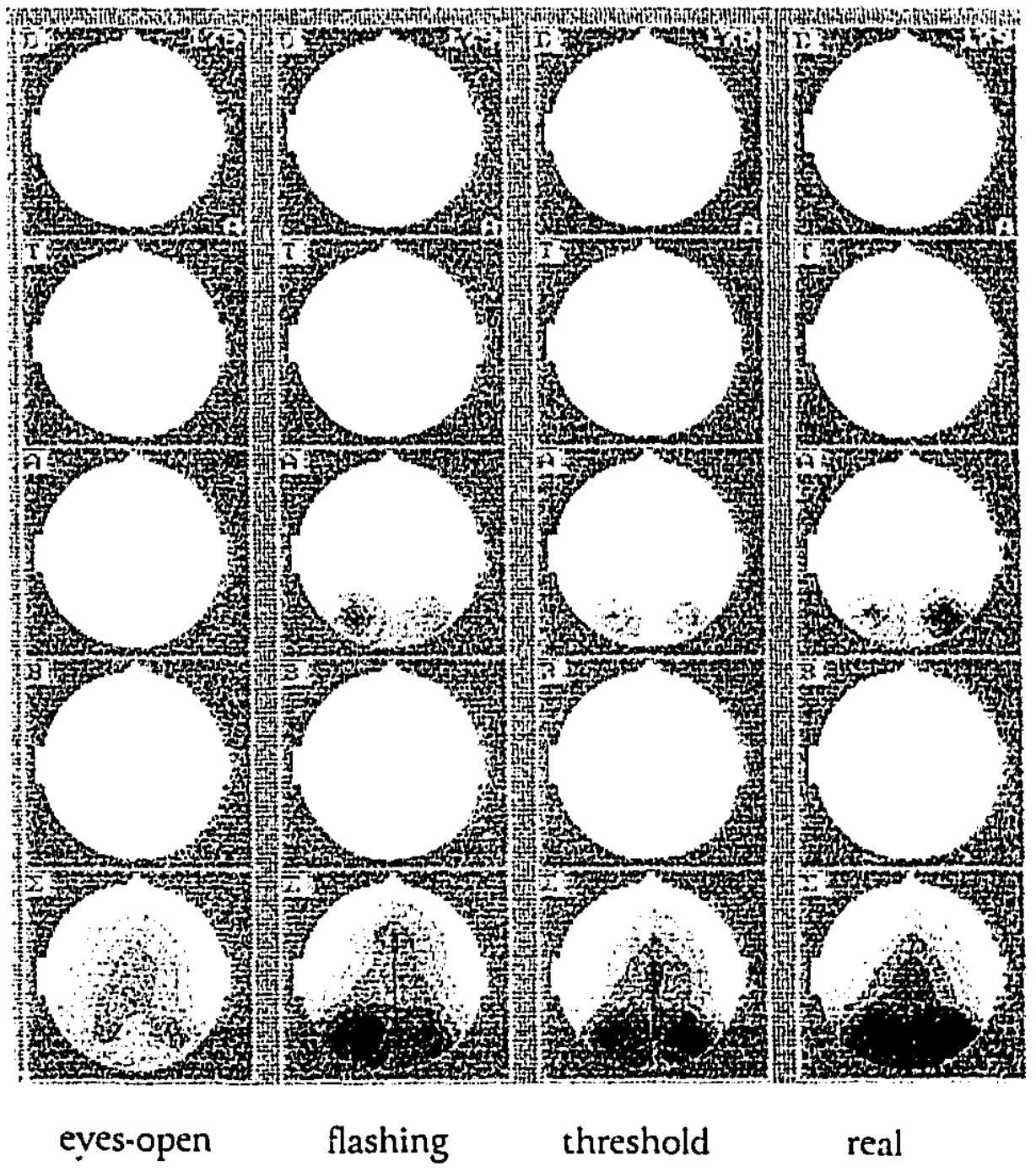

Figure 9

TOPOGRAPHIC BRAIN MAP OF SUBJECT \# 5 


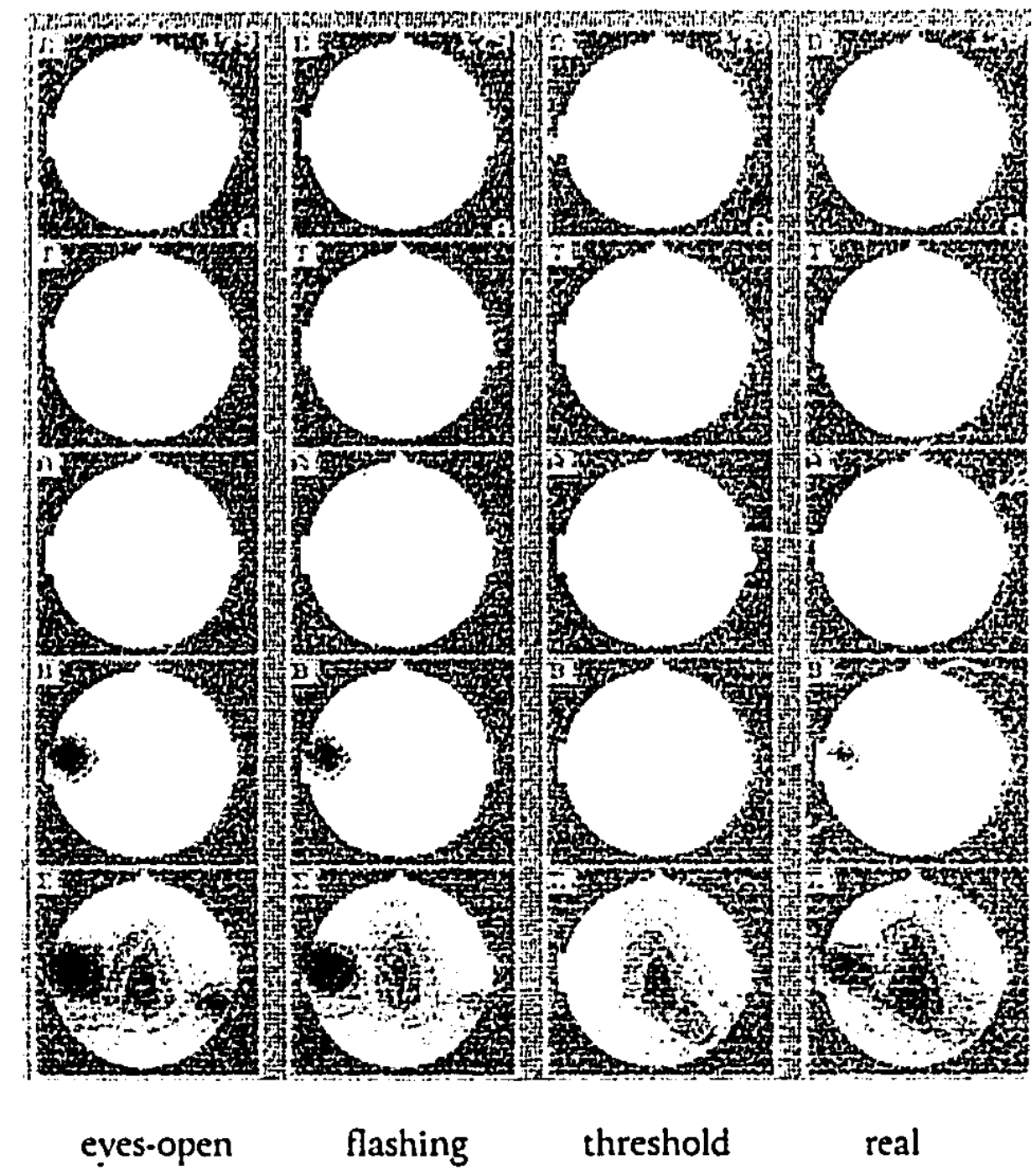

Figure 10

TOPOGRAPHIC BRAIN MAP OF SUBJECT \# 6 
Though there seems to be a possible underlying relationship between alpha and theta power between the reported threshold of perceived movement and real movement the results are not definite. There was a problem in how subjects reported the first perception of movement. In one case where a subject seemed to be unclear in two conditions if movement had occurred, the first condition where there was uncertainty was used as the threshold. Some subjects seemed unsure when to report movement. Since the reporting system was unstructured, the subjective thresholds were unclear. For this reason it was decided to limit the use of subjective tinreshold in further analyses.

\section{Analyses By Experimental Condition}

\section{Comparison of Eyes Open to the Three Experimental Conditions}

To try to get a better understanding of the significant differences obtained in the previous conditions a comparison of eyes-open looking at the computer screen was compared to the three experimental conditions: seeing a circular object flashing, perceiving movement, and perceiving real movement.

\section{Frontal Area}

After having examined the frontal alpha power, significant differences were found in all conditions compared to eyes-open. For the eyes-open condition 
compared to seeing a circular object flashing, three of the six subjects had significant increases in frontal alpha (see Table 2).

TABLE 2

Alpha Power in the Frontal and Occipital Area

Comparison Between Eyes-Open and Seeing a Flashing Object

\begin{tabular}{|c|cccc|cccc|}
\hline & \multicolumn{4}{|c|}{ Frontal Alpha } & \multicolumn{4}{c|}{ Occipital Alpha } \\
Subject No. & Mdiff & $S D$ & $t$ & $p$ & Mdiff & $S D$ & $t$ & $p$ \\
\hline 1 & -0.611 & 0.765 & -2.114 & 0.079 & -1.065 & 1.322 & -1.139 & 0.458 \\
\hline 2 & -1.319 & 0.587 & -5.946 & 0.001 & -1.095 & 6.413 & -0.241 & 0.849 \\
\hline 3 & -6.739 & 2.935 & -6.074 & $0.001^{*}$ & -28.760 & 6.251 & -6.507 & 0.097 \\
\hline 4 & 1.964 & 3.858 & 1.347 & 0.227 & -25.050 & 8.994 & -3.939 & 0.158 \\
\hline 5 & -2.427 & 1.567 & -4.097 & $0.006^{*}$ & -48.625 & 21.843 & -3.148 & 0.196 \\
\hline 6 & 0.164 & 0.922 & 0.471 & 0.654 & 4.825 & 4.999 & 1.365 & 0.403 \\
\hline
\end{tabular}

$p<0.05$

In the comparison of the eyes-open condition to the threshold of perceiving movement three of the six subjects had a significant increase in their frontal alpha (see Table 3). 
TABLE 3

Alpha Power in the Frontal and Occipital Area

Comparison Between Eyes-Open and the Threshold of Perceived Movement

\begin{tabular}{|c|c|c|c|c|c|c|c|c|}
\hline Subject No. & \multicolumn{4}{|c|}{ Frontal Alpha } & \multicolumn{4}{|c|}{ Occipital Alpha } \\
\hline 1 & -2.111 & 2.245 & .2 .489 & $0.047^{\star}$ & .7 .110 & 0.566 & $\cdot 17.775$ & $0.030^{\circ}$ \\
\hline 2 & -2.723 & 1.170 & -0.158 & $0.001^{*}$ & -1.745 & 4.858 & -0.508 & 0.701 \\
\hline 3 & -12.143 & 4.066 & ; -7.901 & $0.000^{*}$ & -41.265 & 6.046 & .9 .0 .53 & 0.060 \\
\hline 4 & -2.326 & 4.546 & -1.353 & 0.225 & .23 .015 & 6.583 & -4.944 & 0.127 \\
\hline 5 & .0 .583 & 1.199 & $\cdot 1.286$ & 0.246 & -33.445 & 9.171 & .5 .157 & 0.122 \\
\hline 6 & .0 .233 & 0.752 & -0.819 & 0.444 & -2.868 & 12.77 & .0 .317 & 0.805 \\
\hline
\end{tabular}

In the comparison of eyes-open condition to perceiving real movement all six subjects had significant increase in their frontal alpha (see Table 4). 


\section{TABLE 4}

Alpha Power in the Frontal and Occipital Area

Comparison Between Eyes-Open and the Perception of Real Movement

\begin{tabular}{|c|c|c|c|c|c|c|c|c|}
\hline Subject No. & Mliff & $\begin{array}{c}\text { Fronta } \\
S D\end{array}$ & $\underset{t}{A}$ Alph & $1 a$ & Mdiff & $\begin{array}{l}\text { Occip } \\
S D\end{array}$ & $\underset{t}{i t a l}$ Alpl & a \\
\hline 1 & .11 .396 & 5.421 & -5.561 & $0.001^{\circ}$ & -14.950 & 1.174 & .18 .012 & $0.035^{\circ}$ \\
\hline 2 & -1.383 & 0.848 & .4 .317 & $0.005^{*}$ & 4.565 & 7.248 & 0.891 & 0.537 \\
\hline 3 & .6 .687 & 2.481 & .7 .133 & $0.000^{*}$ & -32.820 & 10.465 & .4 .435 & 0.141 \\
\hline 4 & -5.931 & 6.403 & -2.451 & $0.050^{*}$ & -16.145 & 0.870 & .26 .575 & $0.024^{*}$ \\
\hline 5 & .4 .774 & 2.340 & .5 .399 & $0.002^{*}$ & -64.335 & 20.966 & -4.340 & 0.144 \\
\hline 6 & .8 .957 & 5.771 & -4.106 & $0.006^{*}$ & -12.030 & 2.899 & -5.868 & 0.107 \\
\hline
\end{tabular}

After having examined frontal theta activity, significant differences were found in all conditions compared to the eyes-open condition. For the eyes-open condition compared to seeing a circular object flashing three of the six subjects had significant difference; of these, one had a significant increase in frontal theta while two had a significant decrease (see Table 5). 
TABLE 5

Theta Power in the Frontal and Occipital Area

Comparison Between Eyes-Open and Seeing a Flashing Object

\begin{tabular}{|c|c|c|c|c|c|c|c|c|}
\hline Subject No. & Miliff & \multicolumn{3}{|c|}{$\begin{array}{l}\text { Frontal Theta } \\
S D \quad t \quad p\end{array}$} & M diff & \multicolumn{3}{|c|}{ Occipital Theta } \\
\hline 1 & -1.473 & 0.798 & .4 .881 & $0.003^{*}$ & -0.780 & 0.948 & .1 .164 & 0.452 \\
\hline 2 & -0.053 & 0.598 & .0 .406 & 0.344 & .0 .610 & 0.051 & -1.326 & 0.411 \\
\hline 3 & -0.130 & 0.851 & -0.320 & 0.760 & -0.565 & 0.346 & -2.306 & 0.206 \\
\hline 4 & 6.486 & 3.340 & 5.138 & $0.002^{*}$ & 3.150 & 1.640 & -2.716 & 0.225 \\
\hline 5 & 1.807 & 1.107 & 4.318 & $0.005^{*}$ & 1.365 & 2.793 & $\left.0.6^{0}\right) 1$ & 0.615 \\
\hline 6 & .0 .614 & 1.071 & -1.518 & 0.180 & -0.865 & 0.332 & -3.681 & 0.161 \\
\hline
\end{tabular}

In the comparison of the eyes-open condtion to the threshold of perceiving movement four of the six subjects had a significant difference in their frontal theta; of these, three had a significant increase in their frontal theta while one had a significant decrease (see Table 6). 
TABLE 6

Theta Power in the Frontal and Occipital Area

Comparison Between Eyes-Open and the Threshold of Perceived Movement

\begin{tabular}{|c|cccc|cccc|}
\hline & \multicolumn{4}{|c|}{ Frontal Theta } & \multicolumn{4}{c|}{ Occipital Theta } \\
Subject No. & Mdiff & $S D$ & $t$ & $p$ & Mdiff & $S D$ & $t$ & $p$ \\
\hline 1 & 0.067 & 0.226 & 0.787 & 0.461 & 1.270 & 0.608 & 2.953 & 0.208 \\
\hline 2 & -1.590 & 0.385 & -10.935 & $0.000^{*}$ & -0.580 & 1.188 & -0.690 & 0.615 \\
\hline 3 & -6.829 & 4.608 & -3.921 & $0.008^{*}$ & -2.160 & 0.339 & -9.000 & 0.070 \\
\hline 4 & 2.786 & 5.837 & 1.263 & 0.254 & -4.500 & 2.220 & -2.866 & 0.214 \\
\hline 5 & 2.004 & 1.275 & 4.160 & $0.006^{*}$ & -1.750 & 1.061 & -2.333 & 0.258 \\
\hline 6 & -0.511 & 0.480 & -2.819 & $0.030^{*}$ & -1.155 & 0.488 & -3.348 & 0.185 \\
\hline$p<0.05$ & & & & & & & & \\
\hline
\end{tabular}

In the comparison of the eyes-open condition to perceiving real movement five of the six subjects had significant differences in their frontal theta; of these, three had a significant increase while two had a significant decrease (see Table 7). 


\section{TABLE 7}

Theta Power in the Frontal and Occipital Area

Comparison Between Eyes-Open and the Perception of Real Movement

\begin{tabular}{|c|cccc|cccc|}
\hline & \multicolumn{4}{|c|}{ Frontal Theta } & \multicolumn{4}{c|}{ Occipital Theta } \\
Subject No. & Mdiff & SD & $t$ & $r$ & Miliff & $S I$ & $t$ & $l$ \\
\hline 1 & -1.740 & 0.603 & -7.629 & $0.000 *$ & -0.895 & 1.039 & -1.218 & 0.438 \\
\hline 2 & -3.244 & 1.042 & -8.235 & $0.000 *$ & -1.490 & 2.008 & -1.049 & 0.485 \\
\hline 3 & -0.220 & 1.00 & -0.528 & 0.582 & 1.275 & 0.502 & 3.592 & 0.173 \\
\hline 4 & 4.024 & 4.033 & 2.640 & $0.039^{*}$ & 1.275 & 0.672 & 2.684 & 0.227 \\
\hline 5 & 1.280 & 0.647 & 5.235 & $0.002 *$ & -1.524 & 0.021 & -101.667 & $0.006 *$ \\
\hline 6 & -11.797 & 5.591 & -5.582 & $0.001 *$ & -6.850 & 4.087 & -2.370 & 0.254 \\
\hline$p\langle 0.05$ & & & & & & & & \\
\hline
\end{tabular}

Throughout these comparisons (see Tables 5, 6, and 7) it was the same two subjects who showed consistent significant decreases.

When an inspection of the topographic brain maps was done fewer differences were observed. In frontal alpha two of the six subjects had observable increases around the central (CZ) to midline frontal (FZ) area. Only one had an increase in frontal theta. When comparing the eyes-open to the reported threshold of perceived movement, two of the six subjects had increases in the frontal alpha power, predominantly in the cental (CZ) to mid frontal (FZ) area. 
Two subjects had an increase in frontal theta power. In the comparison of eyesopen to real movement four of the six subjects had an observable increase in fruntal alpha, again around the cental (CZ) to mid frontal (FZ) area. Four of the six subjects had observable increases in frontal theta power in the same areas (Figures $5 \cdot 10$ ).

\section{Occipital Area}

After having examined occipital alpha activity, few significant differences were found in all conditions compared to the eyes-open condition. For the eyesopen condition compared to seeing a circular object flashing no significant differences were found (see Table 2). In the comparison of the eyes-open condition to the threshold of perceiving movement one out of the six subjects had significant differences in their occipital alpha (see Table 3). In the comparison of the eyes-open condition to perceiving real movement two out of the six subjects had a significant increase in their occipital alpha (see Table 4).

After having examined occipital theta activity, few significant differences were found in all conditions compared to the eyes open condition. For the eyesopen condition compared to seeing a circular object flashing no significant differences were obtained (see Table 5). In the comparison of the eyes-open condition to the threshold of perceiving movement no significant differences were 
found (see Table 6). In the comparison of the eyes-open condition to perceiving real movement one out of the six subjects had a significant increase in occipital theta (see Table 7).

When an inspection of the topographic brain maps was done some observable differences were noticed even though most had been non significant in the statistical analysis. In the comparison of the eyes-open condtion to the reported threshold of perceived movement, one subject had a predominatly right occipital alpha increase. In the comparison of the eyes-open condition to real movement, two subjects had a predominantly right occipital alpha increase while one had a predominantly left occipital alpha increase. No observable differences were detected in frontal theta power (see Figures $5-10$ ).

Comparison between seeing a flashing object and the threshold of perceiving movement

All frontal and occipital electrode leads of each subject were compared between two conditions: seeing an object flashing and the reported threshold of perceived movement. The threshold was determined to be the first point at which subjects reported perceiving some movement.

\section{Frontal Area}

When correlated $t$-tests were conducted for each subject between seeing a flashing circular object and the reported threshold of perceived movement, 
significant differences were obtained for frontal alpha. Four out of the six subjects had a significant difference in frontal alpha power; of these, three had a significant increase in their frontal alpha, while one had a significant decrease (see Table 8).

\section{TABLE 8}

\section{Alpha Power in the Frontal and Occipital Area}

Comparison Between Seeing a Flashing Object and the Threshold of Perceived movement

\begin{tabular}{|c|cccc|cccc|}
\hline & \multicolumn{4}{|c|}{ Frontal Alpha } & \multicolumn{4}{c|}{ Occipital Alpha } \\
Subject No. & Mdiff & $S D$ & $t$ & $p$ & Mdiff & $S D$ & $t$ & $p$ \\
\hline 1 & -1.50 & 1.616 & -2.455 & $0.049^{*}$ & -6.045 & 1.888 & -4.528 & 0.138 \\
\hline 2 & -1.404 & 1.596 & -2.328 & 0.059 & -0.650 & 1.556 & -0.591 & 0.660 \\
\hline 3 & -5.404 & 2.325 & -6.149 & $0.001^{*}$ & -12.505 & 12.297 & -1.438 & 0.387 \\
\hline 4 & -4.290 & 3.068 & -3.707 & $0.010^{*}$ & 2.035 & 2.411 & 1.194 & 0.444 \\
\hline 5 & 1.844 & 0.793 & 6.154 & $0.001^{*}$ & 15.180 & 12.671 & 1.694 & 0.339 \\
\hline 6 & -0.397 & 0.688 & -1.528 & 0.177 & -7.690 & 7.728 & -1.398 & 0.395 \\
\hline$p<0.05$ & & & & & & & & \\
\hline
\end{tabular}

In the comparison of the theta rhythm between these conditions, four of six subjects had a significant difference in their theta power; of these, two had a significant decrease, while two had a significant increase in their frontal theta power (see Table 9). 
TABLE 9

Theta Power in the Frontal and Occipital Area

Comparison Between Seeing a Flashing Object and the Threshold of Perceived Movement

\begin{tabular}{|c|cccc|cccc|}
\hline & \multicolumn{4}{|c|}{ Frontal Theta } & \multicolumn{4}{c|}{ Occipital Theta } \\
Subject No. & Mdiff & $S D$ & $t$ & $p$ & Mdiff & $S D$ & $t$ & ${ }^{\prime}$ \\
\hline 1 & 1.540 & 0.840 & 4.837 & $0.003 *$ & 2.050 & 0.339 & 8.542 & 0.074 \\
\hline 2 & -1.537 & 0.549 & -7.414 & $0.000 *$ & 0.030 & 0.537 & 0.079 & 0.950 \\
\hline 3 & -6.726 & 4.199 & -4.237 & $0.005^{*}$ & -1.595 & 0.686 & -3.289 & 0.188 \\
\hline 4 & -3.700 & 3.331 & -2.939 & $0.026^{*}$ & -1.350 & 0.580 & -3.293 & 0.188 \\
\hline 5 & 0.197 & 0.244 & 2.135 & 0.077 & -3.115 & 3.854 & -1.143 & 0.458 \\
\hline 6 & 0.103 & 1.279 & 0.213 & 0.839 & -0.290 & 0.156 & -2.636 & 0.231 \\
\hline$p\langle 0.05$ & & & & & & & & \\
\hline
\end{tabular}

When an inspection of the topographic brain maps was done similar results were observed. In the visual inspection of the data it seemed that the most predominant changes occurred around the central (CZ) to mid frontal (FZ) area (see Figures $5-10$ ). 


\section{Occipital Area}

When correlated $t$-tests were conducted for each subject between seeing a flashing circular object and the reported threshold of perceived movement no significant differences were found (see Table 8).

In examining the theta activity no significant differences were found (see Table 9).

When an inspection of the topographic brain maps was done, some observable differences were noticed, though statistically they were not signinicant. Two subjects had a lateralized change to the right occipital area (see Figures 5 10).

\section{Comparison Between Perceiving Flashing Objects and Real Movement}

All frontal and occipital electrode leads of each subject were compared between two conditions: seeing an object flashing and the perception of real movement. Real movement was defined as condition number 4 where stimuli overlapped causing blurring of the previously presented stimuli and when the subjects perceived this to be smooth movement.

\section{Frontal Area}

When correlated $t$-tests were conducted for each subject between seeing a circular object flashing and the perception of real movement significant differences 
were obtained for frontal alpha power. Four of the six subjects had significant increases in frontal alpha (see Table 10).

TABLE 10

Alpha Power in the Frontal and Occipital Area

Comparison Between Seeing a Flashing Object and the Perception of Real Movement.

\begin{tabular}{|c|c|c|c|c|c|c|c|}
\hline \multirow[b]{2}{*}{ Subject No. } & \multirow[b]{2}{*}{ Mdiff } & \multirow{2}{*}{\multicolumn{3}{|c|}{$\underset{S D}{\text { Frontal Alpha }}$}} & \multicolumn{3}{|c|}{ Occipital Alpha } \\
\hline & & & & $p$ & Miliff & $S D$ & $p$ \\
\hline 1 & -10.784 & 5.012 & -5.693 & $0.001^{*}$ & -13.885 & $0.148-132.238$ & $0.005^{*}$ \\
\hline 2 & .0 .064 & 1.277 & .0 .133 & 0.898 & 5.660 & $0.834 \quad 9.593$ & 0.066 \\
\hline 3 & 0.051 & 0.870 & 0.156 & 0.881 & -4.060 & $4.214 \quad-1.362$ & 0.403 \\
\hline 4 & -7.896 & 4.931 & .4 .237 & $0.005^{*}$ & 8.905 & $8.125 \quad 1.550$ & 0.365 \\
\hline 5 & -2.347 & 1.065 & -5.829 & $0.001^{*}$ & -15.710 & $42.808 \quad-0.519$ & 0.695 \\
\hline 6 & -9.121 & 5.511 & .4 .379 & $0.005^{*}$ & -16.855 & $2.100-11.350$ & 0.056 \\
\hline
\end{tabular}

In the comparison of theta power among these conditions, four of six subjects had a significant increases in their theta power (see Table 11). 


\section{TABLE 11}

Theta Power in the Frontal and Occipital Area

Comparison Between Secing a Flashing Object and the Perception of Real Movement

\begin{tabular}{|c|c|c|c|c|c|c|c|c|}
\hline Subject No. & \multicolumn{4}{|c|}{ Frontal Theta } & \multicolumn{4}{|c|}{ Occipital Theta } \\
\hline 1 & .0 .267 & 1.32 .5 & .0 .534 & 0.61 .3 & .0 .1115 & 0.092 & -1.769 & 0.328 \\
\hline 2 & .3 .191 & 0.990 & -8.532 & $0 .(600)^{\circ}$ & 0.880 & 1.358 & .0 .917 & 0.528 \\
\hline 3 & -0.117 & 0.569 & -0.544 & 0.606 & 1.840 & 0.156 & 16.727 & $0.038^{*}$ \\
\hline 4 & -2.461 & $! .071$ & -0.082 & $0 .(0) 1^{\bullet}$ & 4.425 & 2.312 & 2.706 & 0.725 \\
\hline 5 & -0.527 & 0.568 & -2.455 & $0.049^{\circ}$ & -2.890 & 2.814 & -1.452 & 0.384 \\
\hline 6 & -11.183 & 0.57 & -4.504 & $0.004^{\circ}$ & -5.985 & 4.419 & -1.915 & 0.300 \\
\hline
\end{tabular}

When an inspection of the topographic brain maps was done fewer observable results were obtained. In the visual inspection of the data it seemed that two subjects had a predominan: increase of frontal alpha around the central (CZ) to mid frontal (FZ) area. One subject increased in theta power predominantly in the central (CZ) to mid frontal (FZ) area (see Figures 5-10).

\section{Occipital Area}

When correlated $t$-tests were conducted for each subject between seeing a 
circular object flashing and perceiving real movement few significant differences were obtained when examining occipital alpha power. One subject had an increase in power (see Table 10).

Again for theta activity few significant differenses were found, one of the six subjects had a decrease in occipital theta power (see Table 11).

When an inspection of the topographic brain maps was done, observable differences were found, though statistically most were not significant. One subject increased predomirantly in the right occipital area, one decreased on the left occipital area and one subject did not have an overall change in alpha power but the lateralization shifted from the left to the right occipital area. In the theta power only one subject had an observable decrease in the occipital region (see Figures $5-10$ ).

\section{Comparison Between Secing the Threshold of Perceiving Movement and Perceiving Real Movement.}

All frontal and occipital electrode leads of each subject were compared between two conditions: the reported threshold of per 'ved movement and real movement. The threshold was determined to be the rirst point at which the subject reported perceiving movement. Real movement was defined as condition number 4 where stimuli overlapped causing blurring of the previously presented stimuli and when subjects perceived this to be smooth movement. 


\section{Frontal Area}

When correlated $t$-tests were conducted for each subject between the reported threshold of perceived movement and perceived real movement significant differences were obtained for frontal alpha power. All of the subjects had significant differences in frontal alpha power; of these four of the six subjects had a significant increase in their frontal alpha, and two had a significant decrease (see Table 12).

TABLE \# 12

Alpha Power in the Frontal and Occipital Area

Comparison Between The Threshold of Perceived movement and Real Movement

\begin{tabular}{|c|cccc|cccc|}
\hline Subject No. & \multicolumn{4}{|c|}{ Frontal Alpha } & \multicolumn{4}{|c|}{ Occipital Alpha } \\
& A.liff & $S D$ & $t$ & $p$ & Mdiff & SD & $t$ & $p$ \\
\hline 1 & -9.284 & 3.629 & -6.768 & $0.001^{*}$ & -7.840 & 1.739 & -6.374 & 0.099 \\
\hline 2 & 1.340 & 0.665 & 5.332 & $0.002 *$ & 6.310 & 2.390 & 3.734 & 0.167 \\
\hline 3 & 5.456 & 2.787 & 5.179 & $0.002^{*}$ & 8.445 & 16.511 & 0.723 & 0.601 \\
\hline 4 & -3.606 & 2.445 & -3.902 & $0.008^{*}$ & 6.870 & 5.713 & 1.700 & 0.338 \\
\hline 5 & -4.191 & 1.624 & -6.827 & $0.000^{*}$ & -30.890 & 30.137 & -1.450 & 0.38 .4 \\
\hline 6 & -8.724 & 5.477 & -4.214 & $0.006^{*}$ & -9.165 & 9.878 & -1.312 & 0.415 \\
\hline
\end{tabular}

$p(0.05$ 
In the comparison of theta power between these conditions, five of six subjects had significant differences in their theta power; of these, three had significant increases, while two had significant decreases in their frontal theta (sce Table 13).

\section{TABLE 13}

Theta Power in the Frontal and Occipital Area

Comparison Between The Threshold of Perceived movement and Real Movement

\begin{tabular}{|c|c|c|c|c|c|c|c|c|}
\hline Subject No. & Muliff & $\begin{array}{c}\text { Front } \\
S D\end{array}$ & al Thet & $p$ & Muliff & $\begin{array}{c}\text { Occip } \\
\text { SI) }\end{array}$ & tal The & , \\
\hline I & -1.807 & 0.724 & -6.605 & $0 .(K) 1^{*}$ & .2 .1605 & 0.431 & -7.018 & 0.089 \\
\hline 2 & -1.6 .54 & 0.816 & 5.364 & $0 .(K) 2$ & -0.910 & 0.820 & $-1.5(60)$ & 0.361 \\
\hline 3 & 6.609 & 4.333 & 4.035 & $0.0017^{\circ}$ & 3.435 & 0.841 & 5.773 & 0.104 \\
\hline 4 & 1.239 & 2.351 & 1.394 & 0.213 & 5.775 & $2.8 \% 2$ & 2.824 & 0.217 \\
\hline 5 & -0.724 & 0.705 & -2.717 & $0.035^{\circ}$ & 0.225 & 1.039 & 0.306 & 0.811 \\
\hline 6 & -11.286 & 5.572 & $-5.35 \%$ & $0.002 *$ & $\mid-5.605$ & 4.575 & $-1.7(x)$ & $0.32 \%$ \\
\hline
\end{tabular}

When an inspection of the topographic brain maps was done similar results were observed. In the visual inspection of the data it seemed that one subject had a predominant increase around the rentral (CZ) to mid frontal (FZ) area. There 
were no other observable difference (see Figures $5-10$ ).

\section{Occipital Area}

When correlated $t$-tests were conducted for each subject between the reported threshold of perceived movement and perceiving real movement no significant differences were found in occipital alpha (see Table 12).

After having examined the theta power no significant differences were found (see Table 13).

When an inspection of the topographic brain maps was done, observable differences were found, though statistically all but one were not significant (see Figures $1-10)$.

\section{Parietal Alpha}

In examining the topographic maps, it was noted that the occipital alpha is more anterior when eyes are open, therefore it was decided to examine if there where any significant differences in the parietal alpha power when comparing the different experimental conditions. When correlated $t$-tests were conducted some significant differences were found, however as with the occipital area, the number of subjects who had significant differences were few.

In the comparison of the eyes-open condition to seeing a circular object 
flashing, three of the six subjects had a significant difference; of these, two had an increase in parietal alpha and one had a significant decrease. In the comparison of the eyes-open condition to the threshold of perceiving movement, one subject had a significant increase. In the comparison of the eyes-open condition to the perception of real movement, two subjects had significant increases (see Table 14).

When a comparison was done between seeing a circular object flashing and the threshold of perceiving movement, one subject had a significant decrease. When a comparison was done between seeing a circular object flashing and the perception of real movement, two subjects had significant increases. In the comparison of the threshold of perceiving movement and the perception of real movement, one subject had an increase (see Table 14).

Overall, slightly more significant differences were found (see Table 15) in parietal alpha than occipital alpha, especially when comparing the eyes-open condition to seeing a circular object flashing. Three subjects had significant differences in their parietal alpha but no subject had a significant difference in occipital alpha. When comparing the other conditions few differences were found in either the parietal or occipital alpha. 
TABLE 14

PARIETAL ALPHA

\begin{tabular}{|c|c|c|c|c|c|c|c|}
\hline Conditions & Stats & $\# 1$ & $\# 2$ & $\# 3$ & $\# 4$ & $\# 5$ & $\# 6$ \\
\hline $\begin{array}{l}\text { cyrs open- } \\
\text { flashing }\end{array}$ & $\begin{array}{c}\text { Maliff } \\
S D \\
t \\
p\end{array}$ & $\begin{array}{l}.6 .157 \\
1.894 \\
.5 .630 \\
0.30\end{array}$ & $\begin{array}{c}-0.233 \\
0.015 \\
-26.458 \\
0.001^{*}\end{array}$ & $\begin{array}{c}-2.717 \\
10.414 \\
-0.452 \\
0.696\end{array}$ & $\begin{array}{c}-2.393 \\
5.384 \\
-0.770 \\
0.522\end{array}$ & $\begin{array}{c}-7.737 \\
4.298 \\
\cdot 3.118 \\
0.089\end{array}$ & $\begin{array}{l}8.127 \\
1.587 \\
8.872 \\
0.012^{\star}\end{array}$ \\
\hline $\begin{array}{l}\text { eyes open- } \\
\text { threshold }\end{array}$ & $\begin{array}{c}\text { Miliff } \\
S D \\
t \\
p\end{array}$ & $\begin{array}{c}.7 .170 \\
2.925 \\
.4 . \because 46 \\
.051\end{array}$ & $\begin{array}{c}-0.290 \\
0.214 \\
-2.350 \\
0.143\end{array}$ & $\begin{array}{c}-12.263 \\
15.419 \\
-1.378 \\
0.302\end{array}$ & $\begin{array}{c}-11.307 \\
1.202 \\
-16.288 \\
0.004^{*}\end{array}$ & $\begin{array}{c}-0.253 \\
5.227 \\
-0.083 \\
0.941\end{array}$ & $\begin{array}{l}2.290 \\
4.752 \\
0.835 \\
0.492\end{array}$ \\
\hline $\begin{array}{l}\text { eyes open- } \\
\text { real }\end{array}$ & $\begin{array}{c}\text { Miliff } \\
S D \\
t \\
p\end{array}$ & $\begin{array}{c}.24 .063 \\
8.48 \\
-4.915 \\
0.039^{*}\end{array}$ & $\begin{array}{c}.0 .227 \\
0.320 \\
-1.227 \\
0.345\end{array}$ & $\begin{array}{c}-19.483 \\
5.527 \\
-6.106 \\
0.026^{*}\end{array}$ & $\begin{array}{c}-13.223 \\
6.844 \\
-3.347 \\
0.079\end{array}$ & $\begin{array}{c}-10.893 \\
5.546 \\
-3.402 \\
0.077\end{array}$ & $\begin{array}{l}-1.637 \\
3.233 \\
-0.877 \\
0.473\end{array}$ \\
\hline $\begin{array}{l}\text { flashing - } \\
\text { threshold }\end{array}$ & $\begin{array}{c}\text { Miliff } \\
S D \\
t \\
p\end{array}$ & $\begin{array}{c}-1.013 \\
1.342 \\
-1.307 \\
0.325\end{array}$ & $\begin{array}{c}-0.057 \\
0.227 \\
-0.433 \\
0.707\end{array}$ & $\begin{array}{c}-9.547 \\
5.435 \\
-3.042 \\
0.093\end{array}$ & $\begin{array}{c}-8.913 \\
6.548 \\
-2.358 \\
0.142\end{array}$ & $\begin{array}{c}7.483 \\
1.530 \\
8.470 \\
0.014^{*}\end{array}$ & $\begin{array}{l}-5.837 \\
3.499 \\
-2.889 \\
0.102\end{array}$ \\
\hline $\begin{array}{l}\text { flashing - } \\
\text { real }\end{array}$ & $\begin{array}{c}\text { Mdiff } \\
S D \\
t \\
p\end{array}$ & $\begin{array}{c}-17.907 \\
0.618 \\
-4.686 \\
0.043^{*}\end{array}$ & $\begin{array}{l}0.007 \\
0.334 \\
0.035 \\
0.976\end{array}$ & $\begin{array}{c}-16.767 \\
14.997 \\
-1.936 \\
0.192\end{array}$ & $\begin{array}{c}-10.830 \\
11.339 \\
-1.654 \\
0.240\end{array}$ & $\begin{array}{c}-3.157 \\
2.825 \\
-1.936 \\
0.193\end{array}$ & $\begin{array}{l}-9.763 \\
2.125 \\
-7.956 \\
0.015^{*}\end{array}$ \\
\hline $\begin{array}{l}\text { threshold - } \\
\text { real }\end{array}$ & $\begin{array}{c}\text { Miliff } \\
S D \\
t \\
p\end{array}$ & $\begin{array}{c}-16.893 \\
5.648 \\
-5.180 \\
0.035^{\circ}\end{array}$ & $\begin{array}{l}0.063 \\
0.110 \\
0.996 \\
0.424\end{array}$ & $\begin{array}{c}-7.220 \\
20.313 \\
-0.616 \\
0.601\end{array}$ & $\begin{array}{c}-1.917 \\
5.813 \\
-0.571 \\
0.626\end{array}$ & $\begin{array}{c}-10.640 \\
1.520 \\
-12.120 \\
0.007^{\circ}\end{array}$ & $\begin{array}{c}-3.927 \\
4.532 \\
-1.501 \\
0.272\end{array}$ \\
\hline
\end{tabular}

${ }^{*} p<0.05$

\section{Summary}

A total of 20 electrodes were utilized for each recording but readings from only nine electrodes were analyzed: the seven associated with the frontal area of 
the brain and the two associated with the occipital area of the brain.

Of the eleven subjects, seven were within the nurmal range for their age groups when compared to the normative database. Four subjects had significant differences when compared to the normative data base and were excluded from the analysis. One subject did not report a threshold of perceived movement and was therefore also excluded from the analysis.

In the experimental conditions, analyses comparing the reported threshold of movement to the other conditions was unclear. This could have been due to the unstructured reporting employed and reflected a high degree of subjectivity.

When comparing seeing a flashing object to the perception of real movement there was a tendency for frontal alpha and theta to increase. No real differences were found for occipital alpha or theta.

When comparing the eyes-open to the experimental conditions there was an obvious trend toward increased frontal alpha. Frontal theta for all but two subjects tended to increases, while two subjects had consistant decreases in theta. There were no appreciable changes in the occipital theta or alpha power. 


\section{Discussion}

\section{Summary of the Research}

This study was concerned with differences in brain activity, measured by quantified electroencephalography while perceiving apparent versus real movement. The hypotheses were developed to discern any significant differences in alpha and theta rhythms in both the frontal and the occipital areas of the brain, among different experimental conditions. The subjects were all volunteer university students. The mean age of the subjects was 24.5 years. All were considered normal with no indications of neurological problems.

All the conditions were generated by animation software and presented on a computer screen. Four different conditions were developed and presented at three different speeds of projection.

Subjects were asked to look at the stimuli while their brain activity was monitored on a computer-based, electrophysical system. All subjects were seated in a dark room and after each stimulus presentation of a white circular on a black backg1 $\quad$ nd the subjects were asked to report what they had seen.

All EEG records were later artifacted to delete any interference from the recordings. The clearest one minute of the record was kept for later analysis. The raw EEG was then subjected to a Fast Fourier Transform, in order to convert the raw EEG data into numerical values. Only absolute power was used in the analyses. 
Summary of the Results

\section{Quantitative Results}

The quantitative results are summarized in Table 14.

\section{TABLE 15}

\section{Summary of Quantitative Results}

$$
(N=6)
$$

\begin{tabular}{|c|c|c|c|c|c|}
\hline $\begin{array}{l}\text { Conditions } \\
\text { Compared }\end{array}$ & $\begin{array}{l}\text { Frontal } \\
\text { Alpha Power }\end{array}$ & $\begin{array}{l}\text { Frontal } \\
\text { Theta Power }\end{array}$ & $\begin{array}{l}\text { Occipital } \\
\text { Npha Power }\end{array}$ & $\begin{array}{l}\text { Occipilal } \\
\text { Theta P'ower }\end{array}$ & $\begin{array}{l}\text { l'arictal } \\
\text { Alplat l'ower }\end{array}$ \\
\hline $\begin{array}{l}\text { Eyes Open to } \\
\text { Flashing }\end{array}$ & $\begin{array}{l}50 \% \text { different } \\
3 \text { increased } \\
0 \text { decreased }\end{array}$ & $\begin{array}{l}50 \% \text { different } \\
1 \text { increased } \\
2 \text { decreased }\end{array}$ & no difference & no difference: & $\begin{array}{l}50 \text { \% different } \\
2 \text { incrensed } \\
1 \text { decrented }\end{array}$ \\
\hline $\begin{array}{l}\text { Fyes Open to } \\
\text { Threshold }\end{array}$ & $\begin{array}{l}50 \% \text { different } \\
3 \text { increased } \\
0 \text { decreased }\end{array}$ & $\begin{array}{l}67 \% \text { different } \\
3 \text { increased } \\
1 \text { decreased }\end{array}$ & $\begin{array}{l}17 \% \text { different } \\
1 \text { increased } \\
0 \text { decreased }\end{array}$ & no difference & $\begin{array}{l}17 \% \text {, differeml } \\
1 \text { increased }\end{array}$ \\
\hline $\begin{array}{l}\text { Eyes Open to } \\
\text { Real }\end{array}$ & $\begin{array}{l}100 \% \text { different } \\
6 \text { increased } \\
0 \text { decreased }\end{array}$ & $\begin{array}{l}83 \% \text { different } \\
3 \text { increased } \\
2 \text { decreased }\end{array}$ & $\begin{array}{l}3.3 \% \text { different } \\
2 \text { increased } \\
0 \text { decreased }\end{array}$ & $\begin{array}{l}17 \% \\
\text { different } \\
1 \text { increased } \\
0 \text { decreased }\end{array}$ & $\begin{array}{l}331 \% \text { different } \\
2 \text { increased }\end{array}$ \\
\hline $\begin{array}{l}\text { Flashing to } \\
\text { Threslinld }\end{array}$ & $\begin{array}{l}67 \% \text { different } \\
3 \text { increased } \\
1 \text { decreased }\end{array}$ & $\begin{array}{l}67 \% \text { different } \\
2 \text { increased } \\
2 \text { decreased }\end{array}$ & $\begin{array}{l}\text { no } \\
\text { difference: }\end{array}$ & $\begin{array}{l}\text { no } \\
\text { difference }\end{array}$ & $\begin{array}{l}17 \% \text { different } \\
1 \text { decreased }\end{array}$ \\
\hline $\begin{array}{l}\text { Flashing to } \\
\text { Real }\end{array}$ & $\begin{array}{l}60 \% \text { different } \\
4 \text { increased } \\
0 \text { decreased }\end{array}$ & $\begin{array}{l}60 \% \text { different } \\
4 \text { increased } \\
0 \text { decreased }\end{array}$ & $\begin{array}{l}17 \% \text { different } \\
1 \text { increase }\end{array}$ & $\begin{array}{l}17 \% \\
\text { different } \\
1 \text { increased }\end{array}$ & $\begin{array}{l}3.3 \% \text { differeml } \\
2 \text { increased }\end{array}$ \\
\hline $\begin{array}{l}\text { Threshold to } \\
\text { Real }\end{array}$ & $\begin{array}{l}100 \% \text { different } \\
4 \text { increased } \\
2 \text { decreased }\end{array}$ & $\begin{array}{l}83 \% \text { different } \\
3 \text { increased } \\
2 \text { decreased }\end{array}$ & no difference & no difference & $\begin{array}{l}3.34, \text { different } \\
2 \text { increased }\end{array}$ \\
\hline
\end{tabular}




\section{Topographic Brain Maps}

Inspection of the topographic brain maps gave an impression of different results when visual inspection was used to determine increases or decreases in alpha and theta power in the different experimental conditions.

One difference, on the brain topographic maps, was that predominant changes appeared to occur around the central $(\mathrm{CZ})$ area to the mid frontal area (FZ). There were also laceralized changes in the right occipital area which was noticeable visually even though no overall statistical significance was found in the alpha and theta power. This difference in lateralization is easily explained by minor changes in head position of the subjects while viewing the stimuli. If the subjects tilted their heads slightly to one side or another, this may have caused lateralization changes.

\section{Interpretations of Findings}

The different results obtained by quantitative analysis and inspection of the topographic brain maps were caused by the significant and non significant differences that are often evident brain maps. It is for this reason that EEG topographic maps should not be the only method of analysis. EEG patterns that are transformed by the Fast Fourier method into numerical values should be used to determine statistical significance (Fisch, 1991). Topographic brain maps allow for a more global view of the brain activity. 
To prevent the masking of individual indifferences it was decided that the results not be pooled, but examined individually. This allowed for a better understanding of changes in alpha and theta power. For some subjects theta and alpha decreased while for other subjects it increased. Were the data pooled, no significant differences would be found. Also, since changes in theta may also depend on personality (Mizuki, Tanaka, Isozaki, Nishijima, Iananaga, 1980), it was preferable to look at the data on an individual basis.

When the eyes-open condition (looking at a blank computer screen) was compared to the various experimental conditions, there was an increase in alpha power especially when compared to the real movement condition. Theta power also exhibited a tendency toward an increase when comparing eyes-open to the threshold of perceived movement and real movement.

The alpha and theta power in the occipital areas were fairly stable throughout all the experimental conditions and few differences were found in the alpha power in the parietal area while significant differences were obtained in the frontal areas. These results suggest a possible higher level cognitive processing when visual stimuli are perceived as moving. This is in line with the findings of Tsude and Ueno (1993) who, using evoked potentials, obtained results that suggested visual apparent movement can be produced in the visual area or higher levels in the central nervous system. 
The increases of alpha power when stimuli are viewed as moving may be explained by the degree of difficulty of the visual task (Osaka, 1984). As the experimental stimuli went from simple (looking at a blank computer screen) to a more complex stimuli (perception of real movement), the alpha power increased.

Decreases in frontal alpha are associated with cognitive tasks such as reading, classification, recognition, and attentional demand (Klimesh, Schimke, \& Pfurtscheller, 1993). The two subjects whose alpha power decreased when viewing real movement compared with the reported threshold may have immediately recognized the final stimuli was moving compared with the previous stimulus, and this may have caused a decrease in their alpha power. However, no firm conclusion can be drawn because of the subjective reporting of threshold of movement. Attentional demand may also explain the various decreases in alpha power throughout the various experimental conditions.

Alpha power has also been correlated with memory and performance (Klimesh, Schimke, \& Pfurtscheller, 1993) and memory may have been a factor in the various experimental conditions. Subjects may have tried to remember the pre; ious stimulus before describing their perceptions. Most of the subjects when describing their perceptions did so comparatively.

Some differences can be detected for the theta power. Unclear results were obtained when comparing seeing a circular object flashing to the reported 
threshold, but then theta seemed to increase in the other experimental conditions. In comparing the eyes-open condition with the three experimental conditions it is interesting to note that two subjects who had significantly different theta power, consistently decreased in power while all other subjects increased in theta power. Further, the more visible changes on the brain maps occurred in the midfrontal areas. Periodic appearance of theta rhythm in the frontal midline area has been observed during performance of mental tasks. No definite cognitive ability has been associated with this frontal midline theta rhythm but some researchers suggest that the appearance of this theta rhythm shows individual differences and there may exist periodicity of an attentional mechanism in certain subjects (Mizuki, Tanaka, Isozaki, Nishijima, \& Inanaga, 1980). They have shown that the appearance or lack of frontal midline theta, as well as duration of theta during a cognitive task, is uependent on personality variables. Frontal midline theta also seems to have an attentional mechanism, with appearnce of theta on a constant periodic time interval, for certain individuals. This may explain why two individuals had a consistent decrease in their theta power (when eyes-open was compared to the other experimental conditions): this may have been due to personality factors or to attentional mechanisms. Further this cculd explain why the theta power results were not as clear as alpha power results. It is suggested that there may be a type of attentional or general cognitive ability associated 
with the perception of real movement.

Relating these findings of the hypotheses presented in Chapter 3, those relating to the occipital area for both alpha and theta power, were supported. In the occipital area no significant differences were found in either thetn or alpha power when comparing the different experimental conditions. The hypotheses relating to the frontal area for both alpha and theta rhythms were not supported. In all cases, when comparing the different experimental conditions, significant differences were found in frontal alpha and theta. The significant differences tended to increase and decrease as previously described depending on the experimental condition but were not as clear as might be hoped.

A conclusion which can be reached from the data analyses is that when a subject sees a stimulus move, there is an increase in frontal alpha and mid-frontal to frontal theta suggesting that higher cognitive processes are involved in perceiving motion.

\section{Implications for Cognitive Research}

As suggested by these findings, the perception of movement seems to involve higher cognitive functions. An interesting issue would be to see how these could augment or hinder learning.

Skrandies and Fakle (1994) have found that stimulus-specific leaming takes 
place in perceptual tasks. Their observations of the changes in electrical brain potentials were interpreted as signs of perceptual learning in the human brain. Most brain activity was largest at the occipital electrodes overlying areas of the primary visual cortex. Also Ramachadran and Anstis (1986) had suggested from their research that the low-level processes can, on their own, control the perception of apparent motion during the early stages of visual perception. If there is stimulus specific learning, and early stages of visual processing of apparent motion is in the occipital areas, is there a time that the perception of movement is leaned in our occipital area? If so, after such perceptual learning takes place when might it require a higher cognitive ability in the frontal area? Might this be a manner which will eventually assist individuals to distinguish between VR and reality?

If indeed memory is an element in the perception of movement, how might the perception of movement affect our memory? Various researchers using mobiles over cribs have found that infants exhibit some form of long term memory when actively involved in controlling the mobiles placed on top of their cribs (cf. Fagen, Yengo, Rovee-Collier, \& Enright, 1981). Could it be that the perception of these mobiles helps stimulate and activate long- term memory in infants? 


\section{Implications for Education}

The perception of movement and the associated increases in alpha and theta power have implications for various special populations. Dyseidetic dyslexia, children with problems in spelling and reading patterns as measured by the Boder criteria, has been associated with a relative inefficiency of the right hemisphere and visual gestalt abilities (Flyn \& Deering, 1989). How does the perception of motion affect their overall learning abilities, does it decrease or augment their learning abilities?

Attention Deficit Hyperactivity Disorder (ADHD) children have an increased theta predominantly in their frontal areas (Mann, Lular, Zimmerman, Milter, \& Muenche, 1991) and others have found more delta, faster theta waves, and fewer alpha waves in ADHD children than in a normal population (Matsura, Okubo, Tora, Kayima, Hou, Shen, \& Lee, 1993). Further, ADHD children on the Bender Visual Motor Gestalt Test lagged behind normal children and many manifest problems with integrating visual perception and fine motor functions. Medicated ADHD children exhibit more problems with visual perceptual integration especially when requiring short-term memory (Risser \& Bower, 1993). For these children the presentation of movement may hinder their learning. Visually presented material or computer generated instruction may further hinder 
their learning abilities.

On the other hand if theta increases and decreases are dependent on individual differences, the perception of movement might decrease theta in ADHD children. Perhaps a new method can be developed to increase their learning -- perhaps flashing rather than static material on a computer screen would help them focus and augment their learning.

\section{Limitations of this Study}

The most obvious limitation of this study is the reporting system used to define the threshold of perceived movement. It was extremely subjective and could be inaccurate. Individuals may have reported perceiving movement after or before their actual threshold. A more objective method of obtaining threshold should be utilized. For example, eye movements might be used as an indicator of when the perception of movement occurred.

Though the frame rate of presentation was held constant for each subject when comparing the different experimental conditions, some subjects did comment on how some stimuli seemed to move faster than others. Speed, therefore, remained a confounding variable which should have been controlled more efficiently.

There were not enough subjects tested to compensate for those who 
deviated significantly from the normative data base and had to be excluded from the final analysis. Other information related to the subjects might have been obtained like a more accurate and complete medical history as well as data on personality factors. This may have been useful in explaining perceptual differences, differences in theta power, and how individuals will convey their uncertainties in perception.

A different statistical approach could be used. Though the statistical method employed is an acceptable method for differentiation, Kamiski, Blair, and Snider (1994) have criticized it as a method where abandonment of data creates the loss of spatial resolution which was gained by using more electrodes. A more complete statistical analysis using data from all the electrodes may be useful.

\section{Suggestions for Future Research}

The first suggestion for future research is to conduct the experiment again adjusting the measurement of threshold and to obtain more information on the subjects. This might allow for a deeper understanding of the perceptual processes of perceiving motion. But there are also other areas which should be explored: special populations, especially dyslexic and ADHD children who have perceptual problems, should be examined.

Dyslexics seem to have gestalt perceptual problems. Presenting material to 
this population via educational films or interactive computer programs may actually cause some to have more or different types of problems. Their learning may actually be decreased rather than augmented.

On the other hand, ADHD children may benefit. from this type of stimulation. The perception of movement or of a flashing stimulus might decrease their theta power.

Further investigation is required to assess how the normal population is affected by these types of visual perceptions. Does movement or the perception of movement help or impede the learning processes? Also, how do perceptions change when objects are viewed in three dimensions rather than two dimensions? To what degree might it be beneficial to the learning process? More attention should also be given to the parietal area.

It may also be beneficial to investigate how personality factors affect theta power, which is closely assosciated with mental tasks.

\section{Conclusion}

From this study it was concluded that the perception of movement involves higher cognitive processes. There seemed to be a difference between the reported threshold of movement and real movement but no definite conclusion can be reached since there was a problem in the way subjects reported their 
threshold. This could explain why monkeys with ablation of their visual cortices can still perceive movement (Milner, 1970).

If movement involves higher cognitive abilities, this may be a way for individuals to learn to differentiate virtual reality and reality. Just as the first time film goers could not differentiate the difference between reality and what was being projected on the screen, a similar problem might emerge distinguishing virutal reality and reality. The main difference is the subjects total immersion in the illusion. It may become important to know the difference between reality and virtual reality to prevent the possible onset of psychotic episodes. Mental health is based on the premise that normal individuals can distinguish between reality and illusion. The immersion of children in an illusionary world without knowing if they can differentiate it from reality, may put their mental health at risk Cartwright \& Silva, 1993; Cartwright 1994). More research is needed to fully understand the implications.

The perception of movement and related abilities have implications for further cognitive research and research on its use in assisting special populations in overcoming their learning difficulties. More research in this area is needed to better understand how to use the EEG technology available to augment learning. 


\section{References}

Anstis, S.M. (1970). Phi movements as a subtraction process. Vision Research, $10,1411-1430$.

Anst.is, S.M. \& Rogers, B.J. (1974). Illusory reversal of visual depth \& movement during changes of contrast. Vision Research, 15, 957-961

Anstis, S.M. (1978). Apparent movement .In Leibowitz, RH. \& Teuber, H.L. (Eds), Handbook of Sensory Physiology, Vol. 8. (pp 656-673). New York: Springer Verlag.

Barlow, J.S. (1993). The electroencephalogram, its patterns and origins. MIT Press, A Bradford Book.

Braddick, O. (1974). A short-range process in apparent motion. Vision Research, 14, 519-528.

Brazier, M.A.B. \& Casby, J.U. (1952). Cross correlation and autocorrelation studies of electroencephalographic potentials. EEG Clinical Neurophysiology, 4, 201-211.

Cartwright, G.F. \& Silva, M. (1993). Virtual reality and consciousness. Paper presented at the Seventh General Assembly of the World Future Society. Washington, D.C.

Cartwright, G. F. (1994). Virtual or real? The mind in cyberspace. The Futurist, $28(2), 22-26$.

Coffin, L. (1993). Topographic Mapping of the Brain Activity of Gifted Children. Unpublished doctoral dissertation, McGill University.

De Silva, H.R. (1929). An analysis of the visual perception of movement. British Journal of Psychology, 36, 265-305.

Dimmick, F.L. \& Scahill, H.G. (1925). Visual perception of movement. American Joumal of Psychology, 36, 412-417. 
Eals, M. (1987). Asymmetric processing in perception of apparent movement. Neuropsychologia, 25 (2), 429-434.

Fabiani, Mu., Gratton, G., Karis, D.,\& Donchin, E.(1987). Definition, identification and reliability of measurement of the P300 component of the event related potential. In Ackles, J. R. Jennings \& M. G. H.Coles (Eds.), Advances in psychophysiology, 2, (pp I -78). London: JAI Press.

Fagen, J.W., Yengo, L.A., Rovee-Collier, C.K., Enright, M.K. (1981).

Reactivaion of a visual discrimination in early infancy. Developmental Psychology, 17 (3), 2ú6-274.

Fisch,W. (1991). Spehlmann's EEG primer (2nd Ed.). Amsterdam: Elsevier

Fisher, K W. (1987). Relations between brain and cognitive development. Chill development, 58, 623-632.

Flynn, J.M., \& Deering, W.M. (1989). Subtypes of dyslexia: investigation of Boder's system using quantitative neurophysiology. Development Medical Child Neurology, 31, 215-223.

Fredman, A. \& Hardy, C.A. (1989). Seeing Versus imaging movement in depth. Canadian Journal of Psychology, 44 (3), 371 -383.

Frisby, J.P. (1971). The effect of stimulus orientation on phi phenomenon. Vision Research, 12, 1145-1166.

Frisby, J.P. \& Clatworthy, J.C. (1973). Real and apparent movement: Evidence for a unitary mechanism. Perception, 2 (2), 161-164.

Gastaut, H., Roger, y., Corriol. J., \& Naquet, R. (1951). Étude électrographic du cycle d'exicitabilité cortical. EEG Clinical Neurophysiology, 3, 401-428.

Gibson, J.J. (1954). The visual perception of objective motion and subjective movement. Psychology Review, 61, 304-314.

Gilmore, G.C., Wenk, H.E., Naylor, L.A.,\& Stuve, T.A. (1992). Motion perception and aging. Psychology and Aging, 7 (4), 654-660. 
Gregory, R.C. (1966). The psychology of secing. London: Weifenfeld \& Nicolson.

Hadley, J.M. (1941). Some relationship between electrical signs of central and peripheral activity during mental work. Joumal of Experimental Psychology, $28,52-62$.

Helsel, S. (1992). Virtual reality and education. Educational Technology, 33 (5), 38.42 .

Huttenlocher, P. R. (1979). Synaptic density in the human frontal cortex: Developmental changes and effects of aging. Brain Research, 195-205.

Huttenlocker, P. R. (1990). Morphometric study of human cerebral cortex development. Neuropsychologia, 28, 517-527.

Hamer, P.F., Sannit, T. (1974). A Review of the International Ten-Twenty System of Electrode Placement. Grass InstrumentCompany.

Hubel, D.H. \& Wiesel, T.N. (1962). Receptive fields, binocular interaction and functional architecture in the cat's visual cortex. Joumal of Physiology, 10, 106-154.

Julesz, B. (1971). Foundations of Cyclopean perception. Chicago: University of Chicago Press.

Jonides, J., Smith, E.E., Koeppe, R.A., Awh, E., Minoshima, S., \& Mintun, M.A. (1993). Spatial working memory in humans as revealed by PET. Nature, $363,623-625$.

Karniski, W., Balir, R C., Snider, A.D. (1994). An exact statistical method for comparing topographic maps, with any number of subjects and electrodes. Brain Topography, 6 (3), 203-210.

Kennedy, J. (1936). The nature and physiological basis of visual movement discrimination in animals. Psychological Review, 43, 494-521.

Klimesch, W., Schimke, H., Pfurtscheller (1993). Alpha Frequency, cognitive load and memory performance. Brain Topography, 5 (3), 241-25l. 
Knott, J.R. (1938). Brain potentials during silent and oral rending. Joumal of General Psychology, 18, 57-62.

Kolers, P.A. (1963). Some differences between real and apparent movement. Vision Research, 3, 191-206.

Kolers, P.A. (1964). Some Illusions of movement. Scientific Amcrica 211 (4), 98 106.

Kolers, P.A. (1972). Aspects of motion perception. Oxford: Pergamon press.

Lake, M. (1994). Dancing postage stamps no more, the fine art of motion video capture and playback. Cutting-Edge Multimedia, March 1994.

Leibowitz, R.H. \& Teuber, H.L. (1978). Handbook of sinsory plysiology, Vol. 8. New York: Springer Verlag.

Mann, C.A., Lubar, F.F., Zimmerman, A.W., Miller, C.A., Muenchen, R.A. (1991). Quantitative analysis of EEG in boys with attention-deficithyperactivity disorder: controlled study with clinical implications. Pediatric Neurology, 8 (1), 30-36.

Matsuura, M., Okubo, Y., Toru, M., Kojima, T., He, Y., Hou, Y., Shen. Y., Lee, C.K (1993). A cross-national EEG study of children with emotional and behavioral problems: a WHO collaborative study in the Western Pacific Region. Biological Psychiatry, 34, 59-65.

McCarthy, G., Blamire, A., Puce, A., Nobre, A.C., Bloch, G., Hyder, F., GoldmanRakic, P.G., \& Schulman, R.G. (1994). Functional magnetic resonance imagine of the human prefrontal cortex activation during a spatial working task. Neurobiology, 91, 8690-8694.

Merickel, M.L. (1992). A study of the relationship between Virtual Reality (perceived realism) and the ability of children to create, manipulate and utilize mental images for spatially related problem solving. A paper presented at the 1992 National School Boards Association Conference. The creative Technologies Project. October 15, 1992.

Milner, P. (1970). Physiological Psychology. New York: Holt Rinehart \& Winston. 
Mundy-Castle, A.C. (1951). Theta and Beta rhythm in the electroencephalograms of normal adults. EEG Clinical Neurophysiology, 3, 447-486.

Mundy-Castle, A.C. (1957). The electroencephalogram and mental activity. EEG Clinical Neurophysiology, 9,645-655.

Niedermeyer, E. \& De Silva, F.C. (1982). Electrocncephalography: basic principles, clinical applications \& Related Fields. Baltimore: Urban \& Schwarzenberg.

Osaka, M. (1984). Peak alpha frequency of EEG during a mental task: task difficulty and hemispheric differences. Psychophysiology, 21 (1), 101-105.

Owen, A.M., Downes, J.J., Sahakian, B.J., Polkey, C.E., \& Robbins, T.W. (1990). Planning and spatial working memory following frontal lobe lesions in man. Neuropsychologia, 28 (10), 1021-1034.

Palmer, L.E. (1909). The world in motion. Survey 22, 355-365.

Pantelidis, V.S. (1993). Virtual Reality in the Classroom. EducationalTechnology, 33 (4), 22-27.

Peterhans, E. \& Heydt, Von Der, R. (1991). Subjective contours bridging the gap between psychophysics \& physiology. Trends in Neuroscience 14 (3), 112 119.

Ramachandran, V.S., \& Anstis, S.M. (1986). The perception of apparent motion. Scientific American, 254 (6), 102-109.

Rebert, C.V., Low, D.W., \& Larsen, F. (1984). Differential hemispheric activation during complex visual motor performance: Alpha trends and theta. Biological Psychology 19 (3), 159-168.

Regian, J.W., Shelbliske, J., \& Monk, J.M. (1992). Virtual Reality: An instructional medium for visual-spatial tasks. Joumal of Communications, 42 (2), 136-149.

Risser, M.G. \& Bowers, T.G. (1993). Cognitive and neuropsychological characteristics of attention deficit hyperactivity disorder children receiving stimulant medication. Perceptual and Motor Skills, 77, 1023-1031. 
Schiffman, H.R (1976). Sensation and perception; an intcgrated approach. New York: John Wiley \& Sons Inc.

Schupp, H.T., Lutzenberger, W., Birbaumer, N., Miltner,W., Braun, C. (1994). Neurophysiological differences between perception and imagery. Cognitiv' Brain Kesearch, 2, 77-86.

Seri, S. \& Cerquiglini, A. (1993). Dynamic changes of Alpha power as a probe of linguistic processes in normal and dyslexic children. Brain Topograplyy, 5 (4), 397-398.

Shepard, R. N., \& Judd, S. A. (1976). Perceptual illusion of rotation of threedimensional objects. Science, 191, 952-954.

Skrandies, W. \& Fahle M. (1994). Neurophysiological correlates of perceptual learning in the Human Brain. Brain Topography, 7, 2, 163-168.

Spring, M. (1991). Information with virtual reality. In Virtual Reality: Theory, Practice \& Promise. S.K. Helsel \& J. P. Ruth. Westport, C.T.: Meckler.

Springer, S.,\& Deutsch, G. (1989). Left brain right brain. New York: W.H. Freeman and Company.

Stauder, J. I. A., Molenaar, P. C. M., \& van der Molen, M.W. (1993). Scalp topography of event-related brain potentials and cognitive transition during childhood. Child Development, 64, 769-788.

Tsude, R. \& Ueno, S. (1993). Spatio-temporal properties of evoked potentials associated with visual apparent movement. Proceedings of the third international congress on BET. Brain Topography, 5 (4), 448.

Uttal, W.R. (1981). A Taxonomy of Visual Processes. Hillsdale, N. J.: Lawrence Erlbaum Associates.

Vorse, M.H. (1911). Some picture show audiences. The Outlook, 98, 441 - 447.

Wade, N.J. \& Swanston, H. (1991). Visual Perception. London: Rutledge.

Wait Disney Company,1991. The Animation Studio. (computer software) 
Winn, W., \& Bricken, W. (1992). Designing virutal worlds for use in mathematics education: Presented at the annual Meeting of the American Educational Research Association. San Francisco. 


\section{APPENDIX A}

\section{TEN-TWENTY SYSTEM OF ELECTRODE PLACEMENT}

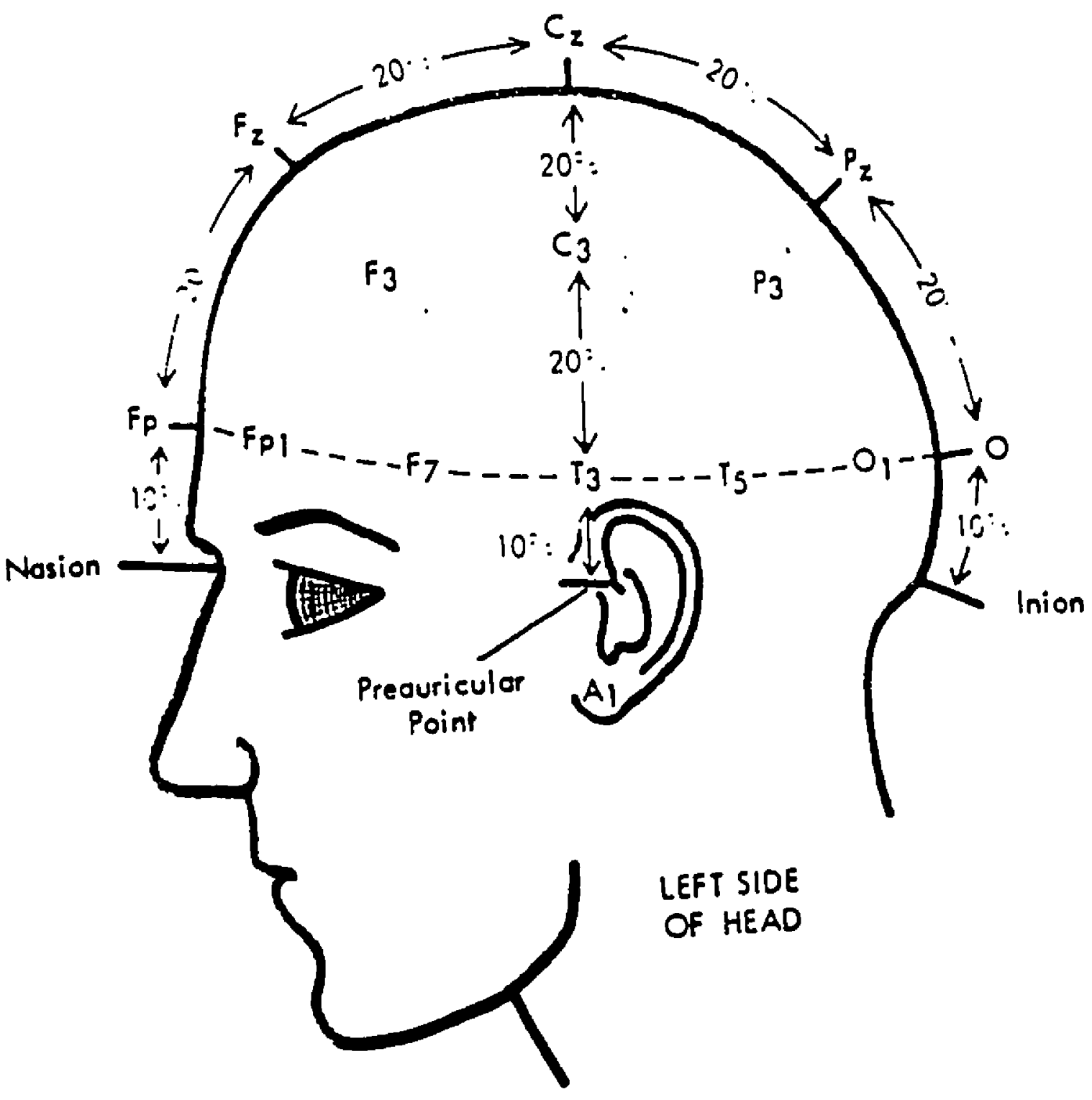

Electrodes are placed either $10 \%$ or $20 \%$ of the total distance between skull landmarks (Harner \& Sannit , 1974). 


\section{APPENDIX B}

FFT data used in the statistical analysis.

Subject \# 1

Absolute Alpha Power

\begin{tabular}{|c|c|c|c|c|}
\hline Electodes & Eyes -Open & Flashing & Threshold & Real \\
\hline $\mathrm{Fp} \mathrm{I}$ & 5.82 & 6.33 & 7.61 & 14.24 \\
\hline Fp 2 & 8 & 7.78 & 7.36 & 16.21 \\
\hline $1: 3$ & 11.04 & 12.5 & 16 & 27.83 \\
\hline $\mathrm{F} 4$ & 12.67 & 12.39 & 14.29 & 26.97 \\
\hline I 7 & 6.02 & 6.93 & 7.63 & 13.91 \\
\hline F 8 & 5.71 & 5.96 & 5.86 & 10.49 \\
\hline $\mathrm{Fz}$ & 12.58 & 14.23 & 17.87 & 31.96 \\
\hline MEAN & 8.83 & 9.44 & 10.94 & 20.23 \\
\hline 01 & 11.81 & 13.81 & 18.52 & 27.59 \\
\hline 02 & 13.65 & 13.78 & 21.16 & 27.77 \\
\hline MEAN & 12.73 & 13.79 & 19.84 & 27.68 \\
\hline p 3 & 11.9 & 18.72 & 18.87 & 37.39 \\
\hline p 4 & 13.46 & 17.48 & 17.81 & 28.42 \\
\hline$p Z$ & 15.83 & 23.43 & 26.02 & 47.57 \\
\hline MEAN & 13.73 & 19.87 & 20.9 & 37.79 \\
\hline
\end{tabular}


Absolute Theta Power

\begin{tabular}{|c|c|c|c|c|}
\hline Electodes & Eyes -Open & Flashing & Threshold & Real \\
\hline Fp 1 & 8.18 & 9.29 & 8.12 & 10.61 \\
\hline Fp 2 & 8.96 & 10.16 & 8.73 & 10.91 \\
\hline F 3 & 18.52 & 20.58 & 18.79 & 19.58 \\
\hline F 4 & 15.34 & 17.45 & 14.91 & 17.08 \\
\hline F 7 & 7.09 & 7.64 & 6.99 & 9.53 \\
\hline F 8 & 6.8 & 7.45 & 6.91 & 8.46 \\
\hline Fz & 23.24 & 25.87 & 23.21 & 24.14 \\
\hline MEAN & 12.59 & 14.06 & 12.52 & 14.33 \\
\hline & & & 132 & 13.42 \\
\hline O 1 & 11.79 & 13.24 & 10.95 & 13.09 \\
\hline O 2 & 13.93 & 14.04 & 12.23 & \\
\hline MEAN & 12.86 & 13.64 & 1.59 & \\
\hline
\end{tabular}


100

Subject \# 2

Absolute Alpha Power

\begin{tabular}{|c|c|c|c|c|}
\hline Electodes & Eyes -Open & Flashing & Threshold & Real \\
\hline Fp 1 & 4.32 & 5.45 & 8.48 & 6.08 \\
\hline Fp 2 & 3.67 & 4.85 & 6.52 & 4.69 \\
\hline F 3 & 7.55 & 8.99 & 8.61 & 7.95 \\
\hline F 4 & 5.72 & 7.67 & 8.54 & 7.81 \\
\hline F 7 & 3.35 & 4.14 & 7.16 & 5.39 \\
\hline F 8 & 3.27 & 3.83 & 6.34 & 5.47 \\
\hline Fz & 8.27 & 10.45 & 9.56 & 8.44 \\
\hline MEAN & 5.16 & 6.48 & 7.88 & 6.54 \\
\hline & & & & \\
\hline O 1 & 9.41 & 15.04 & 14.59 & 9.97 \\
\hline O 2 & 19.36 & 15.92 & 17.67 & 9.64 \\
\hline MEAN & 14.38 & 15.48 & 16.13 & 9.8 \\
\hline & & & & 8.05 \\
\hline p 3 & 7.68 & 7.9 & 8.04 & 8.5 \\
\hline p 4 & 6.05 & 6.28 & 6.51 & 6.5 \\
\hline p Z & 8.67 & 8.87 & 8.67 & 8.48 \\
\hline MEAN & 7.45 & 7.68 & 7.74 & 7.67 \\
\hline
\end{tabular}




\section{1}

Absolute Theta Power

\begin{tabular}{|c|c|c|c|c|}
\hline Electodes & Eyes -Open & Flashing & Threshold & Real \\
\hline Fp 1 & 7.3 & 7.77 & 9.44 & 12.24 \\
\hline Fp 2 & 6.79 & 6.68 & 8.75 & 11.23 \\
\hline F 3 & 12.65 & 13.09 & 13.86 & 15.21 \\
\hline F 4 & 10.91 & 10.51 & 12.59 & 13.44 \\
\hline F 7 & 4.71 & 4.86 & 6.12 & 6.98 \\
\hline F 8 & 5.35 & 5.03 & 7 & 8.06 \\
\hline F & 14.49 & 14.63 & 15.57 & 17.75 \\
\hline MEAN & 8.88 & 8.93 & 10.47 & 12.13 \\
\hline & & & & \\
\hline O 1 & 3.8 & 4.87 & 5.22 & 6.71 \\
\hline O 2 & 4.33 & 4.48 & 4.07 & 4.4 \\
\hline MEAN & 4.06 & 4.67 & 4.64 & 5.55 \\
\hline
\end{tabular}


102

Subject \# 3

Absolute Apha Power

\begin{tabular}{|c|c|c|c|c|}
\hline Electodes & Eyes -Open & Flashing & Threshold & Real \\
\hline $\mathrm{Fp}_{1}$ & 9.13 & 16.27 & 22.16 & 15.14 \\
\hline Fp 2 & 7.6 & 14.77 & 19.45 & 13.97 \\
\hline F 3 & 16.75 & 24.62 & 32.66 & 24.24 \\
\hline F 4 & 11.1 & 19.21 & 22.32 & 19.92 \\
\hline F 7 & 14.46 & 16.59 & 24.02 & 17.52 \\
\hline F 8 & 6.64 & 10.4 & 12.18 & 11.29 \\
\hline$F_{2}$ & 21.11 & 32.1 & 39 & 31.52 \\
\hline MEAN & 12.39 & 19.13 & 24.54 & 19.08 \\
\hline 01 & 40.17 & 73.35 & 77.16 & 80.39 \\
\hline 02 & 28.46 & 52.8 & 74 & 53.88 \\
\hline MEAN & 68.63 & 63.07 & 75.58 & 67.13 \\
\hline p 3 & 34.96 & 32.12 & 36.48 & 60.41 \\
\hline p 4 & 27.74 & 42.47 & 57.67 & 42.28 \\
\hline $\mathrm{pZ}$ & 35.82 & 32.08 & 41.16 & 54.28 \\
\hline MEAN & 32.84 & 35.55 & 45.1 & 52.32 \\
\hline
\end{tabular}


Absolute Theta Power

\begin{tabular}{|c|c|c|c|c|}
\hline Electodes & Eyes -Open & Flashing & Threshold & Real \\
\hline Fp 1 & 7.09 & 7.63 & 20.83 & 7.36 \\
\hline Fp 2 & 5.36 & 6.29 & 18.5 & 6.32 \\
\hline F 3 & 14.63 & 13.86 & 19.61 & 14.09 \\
\hline F 4 & 9.3 & 10.23 & 14.09 & 10.09 \\
\hline F 7 & 11.46 & 10.15 & 14.59 & 10.09 \\
\hline F 8 & 4.62 & 4.77 & 7.48 & 4.46 \\
\hline Fz & 18.65 & 18.9 & 23.81 & 20.24 \\
\hline MEAN & 10.15 & 10.26 & 16.98 & 10.37 \\
\hline & & & & \\
\hline O 1 & 27.66 & 27.98 & 30.06 & 80.39 \\
\hline O 2 & 19.15 & 19.96 & 21.07 & 53.88 \\
\hline MEAN & 23.4 & 23.97 & 25.56 & 22.13 \\
\hline
\end{tabular}


Subject \# 4

Absolute Alpha Power

\begin{tabular}{|c|c|c|c|c|}
\hline Electodes & Eyes -Open & Flashing & Threshold & Real \\
\hline Fp 1 & 22.85 & 14.36 & 20.08 & 22.83 \\
\hline Fp 2 & 20.43 & 15.07 & 17.67 & 21.39 \\
\hline F 3 & 23.49 & 21.54 & 29.04 & 32.11 \\
\hline F 4 & 24.49 & 27.7 & 30.23 & 34.9 \\
\hline F 7 & 9.52 & 8.41 & 11.12 & 11.78 \\
\hline F 8 & 9.34 & 9.02 & 9.3 & 11.32 \\
\hline Fz & 36.68 & 36.95 & 45.64 & 53.99 \\
\hline MEAN & 20.97 & 19 & 23.29 & 26.9 \\
\hline O & & & & 49.36 \\
\hline O 1 & 33.83 & 52.52 & 52.19 & 50.72 \\
\hline O 2 & 33.96 & 65.37 & 61.63 & 51.61 \\
\hline PEAN 3 & 33.89 & 58.94 & 56.91 & 55.6 \\
\hline p Z & 34.34 & 35.65 & 59.04 & 54.04 \\
\hline
\end{tabular}


Absolute Theta Power

\begin{tabular}{|c|c|c|c|c|}
\hline Electodes & Eyes -Open & Fiashing & Threshold & Real \\
\hline Fp 1 & 34.05 & 22.18 & 24.28 & 23.63 \\
\hline Fp 2 & 31.86 & 21.27 & 22.15 & 23.26 \\
\hline F 3 & 35.72 & 30.32 & 37.04 & 34.14 \\
\hline F 4 & 32.38 & 28.79 & 33.86 & 31.84 \\
\hline F 7 & 16.29 & 11.18 & 12.23 & 12.85 \\
\hline F 8 & 15.51 & 10.35 & 11.24 & 11.8 \\
\hline Fz & 54.86 & 51.18 & 60.37 & 54.98 \\
\hline MEAN & 31.52 & 25.03 & 28.73 & 27.5 \\
\hline & & & & 27.06 \\
\hline O 1 & 24.13 & 26.12 & 29.87 & 23.33 \\
\hline O 2 & 23.8 & 28.11 & 28.46 & 22.69 \\
\hline MEAN & 23.96 & 27.11 & & \\
\hline
\end{tabular}


106

Subject \# 5

Absolute Alpha Power

\begin{tabular}{|c|c|c|c|c|}
\hline Electodes & Eyes -Open & Flashing & Threshold & Real \\
\hline $\mathrm{Fp} 1$ & 4.99 & 7.96 & 6.02 & 9.04 \\
\hline $\mathrm{Fp} 2$ & 5.65 & 8.92 & 7.14 & 10.67 \\
\hline $\mathrm{F} \mathrm{3}$ & 10.55 & 12.69 & 10.16 & 15.21 \\
\hline $\mathrm{F} \mathrm{4}$ & 10.88 & 14.24 & 12.79 & 17.69 \\
\hline $\mathrm{F} 7$ & 6.7 & 6.25 & 5.14 & 7.7 \\
\hline $\mathrm{F} \mathrm{8}$ & 6.21 & 7.62 & 6.69 & 9.79 \\
\hline $\mathrm{Fz}$ & 13.83 & 18.12 & 14.95 & 22.13 \\
\hline MEAN & 8.4 & 10.82 & 8.98 & 13.17 \\
\hline & & & & \\
\hline $\mathrm{O} 1$ & 51.32 & 115.39 & 91.25 & 100.83 \\
\hline $\mathrm{O} 2$ & 55.54 & 88.72 & 82.5 & 134.7 \\
\hline MEAN & 53.43 & 102.05 & 86.87 & 117.76 \\
\hline & & & & \\
\hline $\mathrm{p} 3$ & 30.57 & 35.57 & 26.32 & 35.73 \\
\hline $\mathrm{p} 4$ & 22.28 & 34.97 & 28.34 & 38.51 \\
\hline $\mathrm{p} \mathrm{z}$ & 28.39 & 33.91 & 27.34 & 22.13 \\
\hline MEAN & 27.08 & 34.81 & 27.33 & 32.12 \\
\hline
\end{tabular}


Absolute Theta Power

\begin{tabular}{|c|c|c|c|c|}
\hline Electodes & Eyes -Open & Flashing & Threshold & Real \\
\hline Fp 1 & 8.22 & 7.04 & 6.83 & 7.54 \\
\hline Fp 2 & 8.63 & 7.7 & 7.82 & 7.97 \\
\hline F 3 & 21.07 & 17.5 & 16.91 & 18.56 \\
\hline F 4 & 17.48 & 16.72 & 16.42 & 16.52 \\
\hline F 7 & 9.15 & 6.81 & 6.83 & 7.69 \\
\hline F 8 & 8.36 & 7.34 & 7.28 & 7.25 \\
\hline F & 28.44 & 25.59 & 25.23 & 26.86 \\
\hline MEAN & 14.47 & 12.67 & 12.47 & 13.19 \\
\hline & & & & 147.37 \\
\hline O 1 & 12.86 & 13.47 & 13.86 & 14.99 \\
\hline O 2 & 13.45 & 10.11 & 15.95 & 14.68 \\
\hline MEAN & 13.15 & 11.79 & 14.9 & \\
\hline
\end{tabular}


Subject \# 6

Absolute Alpha Power

\begin{tabular}{|c|c|c|c|c|}
\hline Electodes & Eyes-Open & Flashing & Threshold & Real \\
\hline Fp 1 & 8.36 & 9.14 & 9.32 & 16.78 \\
\hline Fp 2 & 8.81 & 9.81 & 9.58 & 14.19 \\
\hline F 3 & 19.09 & 17.55 & 19.33 & 23 \\
\hline F 4 & 10.52 & 10 & 10.23 & 20.02 \\
\hline F 7 & 5.61 & 5.88 & 6.28 & 24.77 \\
\hline F 8 & 5.99 & 5.82 & 6.47 & 19.43 \\
\hline $\mathrm{Fz}$ & 19.68 & 18.71 & 18.48 & 22.57 \\
\hline MEAN & 11.15 & 10.98 & 11.38 & 20.1 \\
\hline 01 & 28.39 & 20.03 & 22.22 & 38.37 \\
\hline $\mathrm{O} 2$ & 22.66 & 21.37 & 34.56 & 36.74 \\
\hline MEAN & 25.52 & 20.7 & 28.39 & 37.55 \\
\hline$p 3$ & 34.7 & 24.91 & 26.96 & 34.43 \\
\hline p 4 & 31.62 & 24.99 & 31.5 & 36.99 \\
\hline $\mathrm{pZ}$ & 36.18 & 28.22 & 37.17 & 35.99 \\
\hline MEAN & 34.16 & 26.04 & 31.87 & 35.8 \\
\hline
\end{tabular}


Absolute Theta Power

\begin{tabular}{|c|c|c|c|c|}
\hline Electodes & Eyes -Open & Flashing & Threshold & Real \\
\hline Fp 1 & 9.08 & 9.87 & 9.54 & 18.84 \\
\hline Fp 2 & 8.86 & 9.29 & 10.3 & 19.4 \\
\hline F 3 & 21.68 & 22.93 & 22.24 & 27.81 \\
\hline F 4 & 11.83 & 11.51 & 12.13 & 27.29 \\
\hline F 7 & 5.73 & 5.57 & 5.8 & 21.38 \\
\hline F 8 & 5.93 & 5.61 & 6.65 & 26.21 \\
\hline Fz & 26.79 & 29.42 & 26.82 & 31.55 \\
\hline MEAN & 12.84 & 13.45 & 13.35 & 24.64 \\
\hline & & & & 104 \\
\hline O 1 & 9.29 & 9.92 & 10.1 & 19.03 \\
\hline O 2 & 8.46 & 9.56 & 9.96 & 12.42 \\
\hline MEAN & 8.87 & 9.74 & 10.03 & 15.72 \\
\hline
\end{tabular}




\section{APPENDIX C}

\section{Letter of Consent}

\section{CONSENT FORM}

We would like to have you participate in a research study. The study will compare the brain activity while viewing a moving geometrical figure on a computer screen. For this study brain activity refers to the electrical activity produced by the brain, which we will measure in a standard fashion but will analyze later using a computer program. The purpose of this study is to determine if there is different brain activity while viewing different variations uf movement on a computer screen. This will greatly contribute to our knowledge of the perception of motion.

As part of this study you will be given a standard EEG

( electroencephalogram) while sitting quietly at rest and while viewing the computer screen. This procedure is non-invasive, painless, and is used in routine evaluation of individuals, hundreds of thousand of times each year in North America. If at any time you no longer wish to continue, the procedure will be terminated and you may withdraw from the study.

All personal and medical information will remain confidential and for the purpose of anonymity you will be assigned an identification number. Your name will not appear on any publication. Nor will your name be used in any analysis, either group or individual, unless you specifically request to do so, in the event that we note any unusual problem that warrants your attention or your physician's.

This study is carried out by the McGill University Department of Educational Psychology and Counselling Psychology.

I, study, , the undersigned, agree to participate in this

Signature:

Date:

I, , the undersigned, agree to participate in this study and request that any clinically relevant information be brought to me or my physician.

Signature:

Date:

Physician:

Tel. No.: 


\section{APPENDIX D}

Certificate of Ethical Approval 